\title{
Review Article \\ Contribution of Microglia-Mediated Neuroinflammation to Retinal Degenerative Diseases
}

\author{
Maria H. Madeira, ${ }^{1}$ Raquel Boia, ${ }^{1}$ Paulo F. Santos, ${ }^{1,2,3}$ \\ António F. Ambrósio, ${ }^{1,2,4}$ and Ana R. Santiago ${ }^{1,2,4}$ \\ ${ }^{1}$ Centre of Ophthalmology and Vision Sciences, IBILI, Faculty of Medicine, University of Coimbra, Azinhaga de Santa Comba, \\ 3004-548 Coimbra, Portugal \\ ${ }^{2}$ Center for Neuroscience and Cell Biology, University of Coimbra, Coimbra, Portugal \\ ${ }^{3}$ Department of Life Sciences, University of Coimbra, Coimbra, Portugal \\ ${ }^{4}$ AIBILI, Coimbra, Portugal
}

Correspondence should be addressed to Ana R. Santiago; asantiago@fmed.uc.pt

Received 5 November 2014; Accepted 16 December 2014

Academic Editor: Kiyoshi Matsumura

Copyright (C) 2015 Maria H. Madeira et al. This is an open access article distributed under the Creative Commons Attribution License, which permits unrestricted use, distribution, and reproduction in any medium, provided the original work is properly cited.

Retinal degenerative diseases are major causes of vision loss and blindness worldwide and are characterized by chronic and progressive neuronal loss. One common feature of retinal degenerative diseases and brain neurodegenerative diseases is chronic neuroinflammation. There is growing evidence that retinal microglia, as in the brain, become activated in the course of retinal degenerative diseases, having a pivotal role in the initiation and propagation of the neurodegenerative process. A better understanding of the events elicited and mediated by retinal microglia will contribute to the clarification of disease etiology and might open new avenues for potential therapeutic interventions. This review aims at giving an overview of the roles of microgliamediated neuroinflammation in major retinal degenerative diseases like glaucoma, age-related macular degeneration, and diabetic retinopathy.

\section{Introduction}

1.1. Retinal Structure and Cell Types. The retina is part of the central nervous system (CNS) due to its neuroectodermal origin and derivation from the anterior neural tube. The mature mammalian retina is structured in nuclear layers of neurons. The outermost layer of the retina is the retinal pigment epithelium (RPE), which is followed by the outer nuclear layer (ONL) that contains the cell bodies of photoreceptors. The inner nuclear layer (INL) contains the cell bodies of the bipolar, horizontal, and amacrine cells, and the ganglion cell layer (GCL) is composed by the nuclei of retinal ganglion cells (RGCs) and of displaced amacrine cells. These cells are interconnected through synapses that occur in the outer and inner plexiform layers (Figure 1). Besides neurons, other cells are present in the retina, such as glial cells (Müller cells, astrocytes, and microglia) and the cells that constitute the retinal vessels (endothelial cells and pericytes). The RPE is a monolayer of cuboid, pigmented cells in which the apical membrane faces the photoreceptor outer segments, with important functions for retinal physiology (reviewed in [1]).

Photoreceptors transduce light energy into electrochemical signals to the second-order neurons, bipolar cells, which synapse with RGCs (vertical pathway). Amacrine and horizontal cells modulate this pathway of information, commonly referred to as the horizontal visual pathway. The axons of RGCs form the optic nerve and extend to the lateral geniculate nucleus (LGN) in the thalamus and the superior colliculus in the midbrain, from which information is further transmitted to the visual processing centers in the visual cortex $[2,3]$.

Müller cells constitute the predominant glia in the vertebrate retina, spanning the entire thickness of the retina. These cells are responsible for the homeostatic and metabolic support of retinal neurons and are involved in the regulation of the synaptic activity in the inner retina [4-6], but they also contribute to increase photon absorption by cones [7]. 

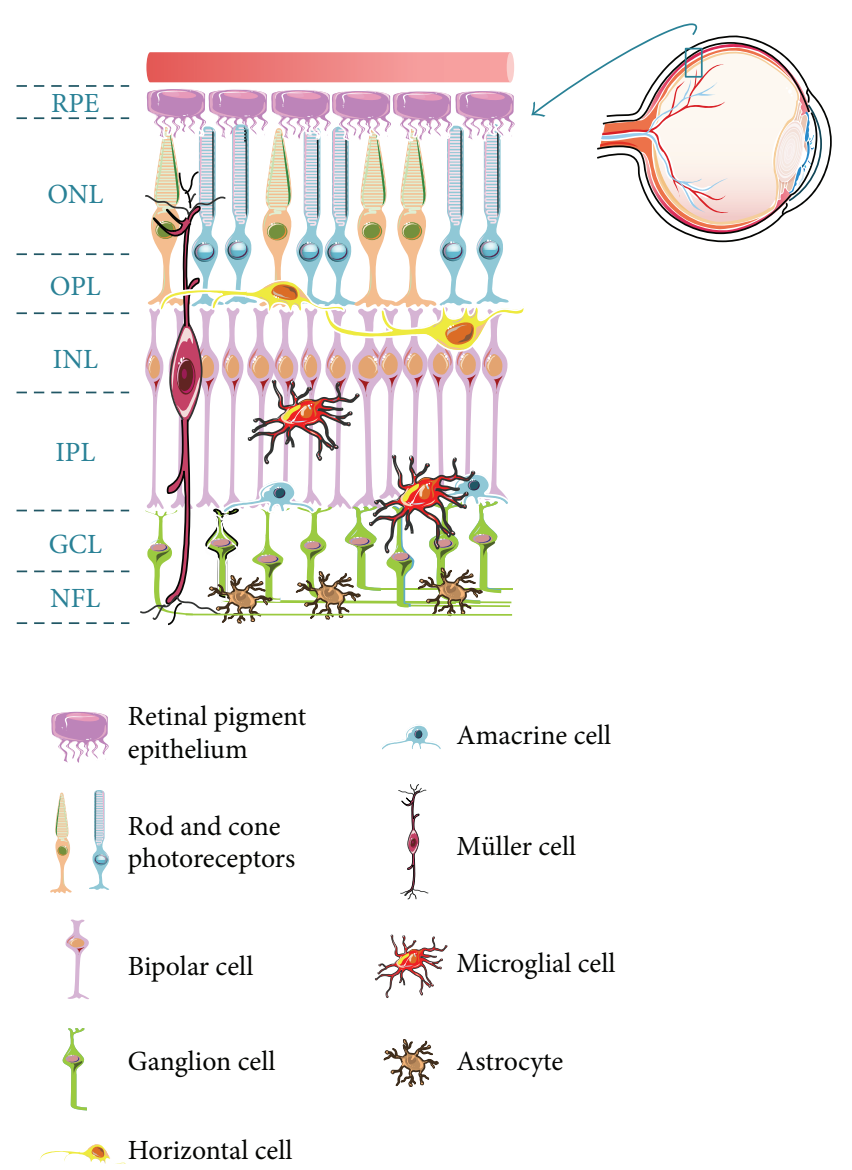

FIGURE 1: Schematic representation of the major retinal cell types and their organization in the retina. The outermost part of the retina is the retinal pigment epithelium (RPE), which consists of a monolayer of cuboid, pigmented cells between the photoreceptors and the choroid. The retina is divided into three laminar layers: the outer nuclear layer (ONL), the inner nuclear layer (INL), and the ganglion cell layer (GCL). The nuclei of rod and cone photoreceptors are located in the ONL. The INL comprises the nuclei of the bipolar, horizontal, and amacrine cells. Cell bodies of the retinal ganglion cells are present in the GCL, and their axons form the nerve fiber layer (NFL), just beneath the GCL. Synapses between photoreceptors and interneurons are located in the outer plexiform layer (OPL) and interneurons synapse with RGC in the inner plexiform layer (IPL). Müller cells span all retinal layers. Microglia are mainly found in IPL and GCL, whereas astrocytes are located near the NFL.

Astrocytes, which have flattened cell bodies and fibrous radiating processes, enter the developing retina from the brain along the developing optic nerve, exerting an important role on structural support of the retina. Together with Müller cells, astrocytes integrate the vascular and neuronal activity of the retina $[6,8]$.

The third type of glial cells is present in the retina is microglia, the tissue-resident immune cells, which are constantly surveying the parenchyma (reviewed in [9]). Microglial cells are crucial effectors and regulators of changes in homeostasis during development and in health and disease. Although the functions of retinal microglia under physiological conditions are not extensively clarified, the importance of the interactions between microglia and both neurons and macroglia to the homeostasis of the retina is strongly recognized. Microglial cells are implicated in many functions essential for the proper development of the CNS, from neurogenesis to synaptic pruning, the process of synapse elimination (reviewed in $[10,11]$ ). In the retina, TGF- $\beta$ may have a role in regulating microglia-mediated synaptic pruning $[12,13]$. Microglial cells are also involved in programmed cell death in the developing retina, and nerve growth factor released by microglia may induce retinal neuronal cell death [14]. Microglial cells interact with neurons in a reciprocal form, by balancing excitatory and inhibitory neurotransmission, which contributes to the maintenance of neuronal activity and microglia homeostasis in the healthy brain (reviewed in [15]). Neurotrophic factors released by microglia have an impact on neuronal physiology and survival. Brain derived neurotrophic factor (BDNF), ciliary neurotrophic factor (CNTF), glial cell line-derived neurotrophic factor (GDNF), NGF, neurotrophin-3 (NT3), and basic fibroblast growth factor (bFGF) have been shown to protect and regulate the survival of photoreceptors [16]. Microglial cells also establish important interactions with Müller cells, regulating the microglia-Müller-photoreceptor network that serves as a trophic factor-controlling system during retinal degeneration [17]. The bidirectional communication between microglia and Müller cells have been suggested to act as a mediator of neuron-microglia interaction, acting as a sensor of neurotransmission signals resulting from neuronal and synaptic activity $[4,18-20]$. Also, Müller cells may provide ATP to the extracellular environment that mediates the activity-dependent regulation of microglial dynamic process motility [19].

\section{Origin of Retinal Microglia}

Microglial cells were first described by Pio del Rio-Hortega in 1932, as a unique cell type that differs from other glial and neuronal cells in morphology and constitutes approximately $5 \%$ to $12 \%$ of the cells of the CNS (reviewed in [21]).

Microglial cells are from mesodermal/mesenchymal origin deriving from myeloid progenitors that migrated from the periphery during late embryonic and postnatal life (reviewed in $[9,22,23])$. Taking into account the similarities between microglia and peripheral macrophages, it is reasonable to understand the major challenge that researchers have been facing to distinguish these two cell types. Nevertheless, recent evidence provided by gene expression profile studies suggest that microglia differs considerably from macrophages allowing the identification of unique molecular signatures $[24,25]$.

Concerning the retina, the precursors of microglia emerge during retinal development, prior to vascularization, via the ciliary margin, and differentiate in ramified, quiescent parenchymal microglia in the adult retina [26]. Radiation bone marrow chimeras have been used to assess microglia turnover and replenishment. Using these models, retinal microglia turnover was reported to take six months in the mouse $[27,28]$ and one year in rats $[27,28]$. However, the use of parabiotic mouse model, which obviates the need for 
irradiation and bone marrow transfer, provided the evidence that under physiological conditions there is no turnover of microglia [29]. Most probably, microglia turnover observed in radiation chimeras is due to irradiation treatment that can act as an insult to the eye, stimulating the turnover of cells derived from bone marrow in ocular tissues [30]. These findings suggest that maintenance and local expansion of microglia are solely dependent on the self-renewal of resident cells.

In the developing retina, microglial cells have been found to be crucial for retinal growth and neurogenesis [31]. Additionally, undifferentiated microglial cells have also been associated with increased production of nitric oxide (NO) [32] and promotion of neuronal cell engulfment during retinal development [33].

In the adult retina, microglial cells are distributed in the plexiform layers, GCL and nerve fiber layer (NFL), showing highly motile protrusions that survey the surrounding environment [26,34-39]. The movement of their processes occurs in all directions, and it is unaccompanied by soma migration [40], suggesting that the process dynamics may also serve to exchange signals between neighboring microglia, and may help explaining laminar retinal microglia distribution [41]. Interestingly, in the adult retina, microglial cells have different morphologies throughout the different layers. In the NFL, microglial cells are scarce and have a bipolar morphology, with long axis parallel to the course of RGC axons. Multipolar microglial cells, with round or oval cell bodies and some main processes, can be found in the GCL. Microglial cells in the IPL have small round cell bodies with three main branches that are stratified and distributed through the entire retina [42].

The functions of microglia in the physiology of the retina are not fully elucidated yet. Nevertheless, microglial cells are required for normal retinal growth and neurogenesis [31] and proper retinal blood vessel formation [43].

\section{Microglia Responses in Neurodegenerative Disorders}

Neurodegeneration describes the slow and progressive dysfunction and loss of neurons or their axons in the CNS. Despite different triggering events, microglia activation is a major characteristic of neurodegenerative conditions, such as Alzheimer's and Parkinson's diseases, traumatic brain injury, and multiple sclerosis (reviewed in [44-47]). Contrary to what happens in conditions of acute inflammation, where microglia activation may have beneficial effects (elimination of pathogens and cell debris), in chronic neuroinflammation microglia activation is usually detrimental, contributing to the pathogenesis of neurodegenerative disorders (reviewed in [22]). Chronic neuroinflammation encompasses overactivated microglial cells releasing proinflammatory mediators and increased oxidative and nitrosative stress [48]. Activated microglial cells can proliferate and migrate to the site of injury, where the morphological alterations are usually accompanied by changes in signaling and gene expression [49]. Usually, upon injury, the levels of CD45 are elevated, making it difficult to distinguish microglia from infiltrating macrophages [50]. Exacerbated and sustained neuroinflammation creates a toxic milieu that may lead to detrimental effects in neuronal cells $[46,51]$.

\section{Retinal Degenerative Diseases and Neuroinflammation}

Nearly 285 million of people have visual impairment, and this number is expected to continue to increase as a result of the ageing of the world's population [52].

Retinal degenerative diseases, such as glaucoma, agerelated macular degeneration (AMD), and diabetic retinopathy, are among the main causes of blindness worldwide [53]. These retinal diseases are characterized by chronic neuroinflammation and microglial cells have a key role in the initiation and perpetuation of the inflammatory response (Figure 2). The overactivation of microglia results in excessive production of inflammatory mediators that accumulate to levels that are harmful to neurons, further contributing to retinal neurodegeneration $[54,55]$.

4.1. Glaucoma. Glaucoma affects approximately 70 million people worldwide and nearly $2 \%$ of the population over the age of $40[56,57]$. Glaucoma is defined as a group of disorders characterized by optic neuropathy with clinically visible alterations at the $\mathrm{ONH}$ encompassing thinning of the neuroretinal rim and excavation of the optic disc and representing progressive loss of RGCs and their axons [58].

Several factors are associated with the development and progression of glaucoma, such as family history, systemic hypertension, diabetes, and cigarette smoking, but the main risk factors are elevated intraocular pressure (IOP), above $21.5 \mathrm{mmHg}$, and age [59]. Current therapeutic approach is focused on lowering IOP by pharmacological means, surgically or with laser treatment. However, despite efficient IOP control, a vast majority of patients continue to lose vision [60], emphasizing the need of alternative drug-based neuroprotective treatments that target RGC apoptosis and inflammatory pathways [61-63].

Neuroinflammation has been recognized as playing an important role in the pathogenesis of glaucoma. Increased levels of inflammatory mediators, such as tumor necrosis factor (TNF) [64-69], interleukin (IL)-6 [69-74], IL-9, IL10 , IL-12 [75], and NO [76, 77], are found in the retina and aqueous humor of patients and in experimental glaucoma.

TNF has been implicated as a mediator of RGC death in glaucomatous retina $[66,78-80]$. Production and release of TNF increase following elevated IOP or ischemia, suggesting TNF as an attractive therapeutic target. Indeed, RGC apoptosis is attenuated by a neutralizing antibody against TNF [81]. Moreover, etanercept (Enbrel), a widely used TNF antagonist, attenuates inflammation and RGC loss in a glaucoma animal model [82]. Recently, it was reported that polymorphisms in IL-1 $\beta$ gene might contribute to the increased risk of primary open angle glaucoma but not to the progression [83]. Inducible nitric oxide synthase (iNOS) is usually upregulated by inflammatory mediators producing large amounts of NO $[84,85]$. Upregulated iNOS and increased NO levels were found in the $\mathrm{ONH}$ of glaucomatous patients [86] and in the retina and $\mathrm{ONH}$ of glaucoma animal models 


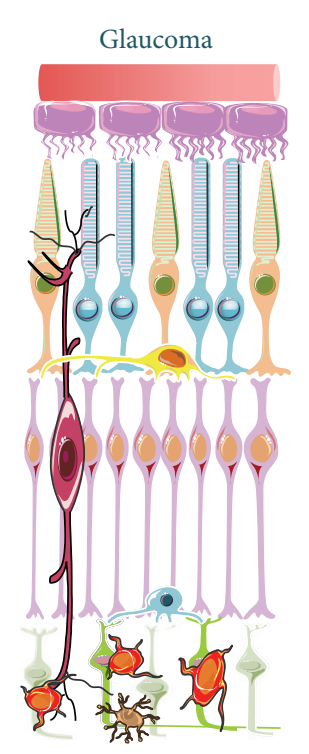

Neurodegeneration of RGCs Activated microglia in GCL

(a)

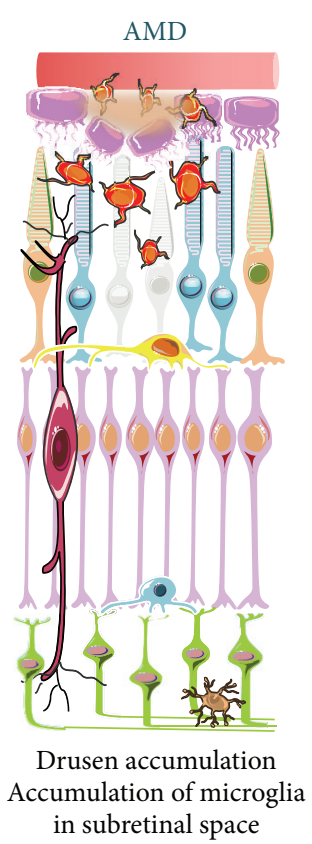

(b)

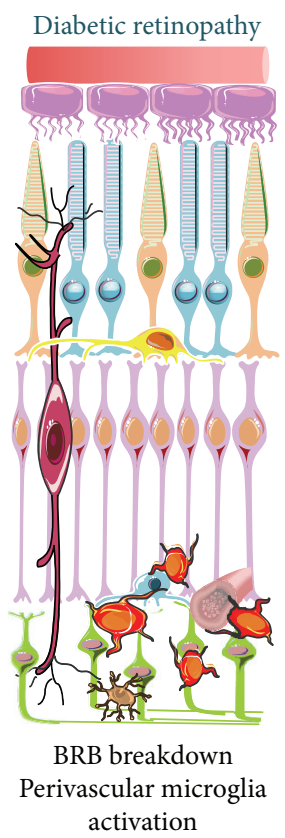

(c)

FIGURE 2: Schematic representation of microglial responses in glaucoma, AMD, and diabetic retinopathy. Reactive microglial cells are found in the retina of patients and animal models of glaucoma (a), AMD (b), and diabetic retinopathy (c). (a) Glaucomatous retinas present abnormally distributed activated microglial cells in the GCL, namely, surrounding the RGC axons and soma. (b) In AMD retinas, microglial cells accumulate in the ONL and subretinal space, surrounding drusen deposits. (c) Increased vascular permeability in diabetic retinopathy is accompanied by perivascular accumulation of activated microglial cells.

$[77,87,88]$. Inhibition of iNOS with aminoguanidine confers neuroprotection to RGCs in an animal model of glaucoma [89], supporting a role of $\mathrm{NO}$ in the pathophysiology of glaucoma.

IL-6 has been proposed has a key component of pressureinduced responses by retinal microglia $[90,91]$. In genetic animal models of glaucoma alterations in the expression of IL-6 and IL-6 receptors have been detected [74]. Similarly, in the aqueous humor of patients with neovascular glaucoma, the levels of IL- 6 increase spatial and temporarily correlated with the grade of neovascularization of the patient [70]. Nevertheless, IL-6 increases the survival of RGCs challenged with pressure, suggesting that it may be an attempt to regenerate RGC axons [73, 91].

Specific changes in autoantibody profiles have been described in glaucomatous patients and animal models [9294], which are associated with antibody depositions in the sera and aqueous humor of glaucomatous patients, and increased microglial cell activation in the retina of experimental models [95]. These changes have been linked with the inflammatory process that precedes RGC degeneration and clearance of cell debris [96].

Microglial cells are considered to have a key role in the inflammatory environment in glaucomatous conditions. Several studies focusing on the role of microglial cells in glaucoma have shown that these cells have alterations in morphology, gene expression, cell proliferation, cell adhesion, and immune response, compatible with a reactive phenotype [89, 97-101]. In fact, growing evidence demonstrates that the interactions between RGCs and glia are critically important for glaucomatous neurodegeneration [98, 102-104].

Abnormal microglia reactivity and distribution have been observed in animal models of RGC degeneration, as the optic nerve axotomy model [105-107] and retinal ischemia [77, 108], suggesting that microglia become reactive secondary to RGC degeneration. Nevertheless, direct evidence of the contribution of microglia to the loss of RGCs in glaucoma was provided by the observations that microglial cells proliferate in the vicinity of RGCs [109] and that the recruitment and activation of microglial cells occurs before RGC death [99]. Additionally, minocycline, a tetracycline derivative known to inhibit microglial activation [110], suppresses RGC neurodegeneration in ischemia and glaucoma models [111-113] and improves the integrity of the optic nerve [104], further supporting a role for microglia to glaucomatous neuropathy. Furthermore, a high-dose of irradiation has been shown to reduce microglia reactivity and proliferation in the central retina and in the $\mathrm{ONH}$ region of animal models of glaucoma [104]. The reduction of microglia reactivity is associated with decrease in RGC degeneration and an improvement of the structural and functional integrity of RGC axons [104].

In eyes from glaucomatous patients, microglial cells present a more amoeboid morphology, clustering in the lamina cribosa and surrounding blood vessels, suggesting a protective role against damage to the blood-retinal barrier (BRB) [114]. In animal models of ocular hypertension [100] and chronic glaucoma [99], microglial cells become reactive and redistribute in the retina, optic nerve, and optic tract 
as early alterations, which may contribute to the disease onset or progression. Furthermore, in animal models of chronic glaucoma, the number of microglial cells double from 4 to 10 months in a reactive, not proliferative, gliosis response [109]. Additionally, in glaucomatous animal models, increased expression of major histocompatibility complex II (MHC-II) and CD200 (markers of activated microglia) is early detected in the retina, namely, adjacent to the optic nerve, suggesting this process accompanies ongoing axonal degeneration [97, 100, 115-118].

Reactive microglial cells are also observed in all retinal layers of eyes contralateral to experimental glaucoma, though with different morphology, suggesting an attempt of maintaining tissue homeostasis, protecting axons of the noninjured eye $[116,117,119]$.

Microglia reactivity in glaucoma is not confined to the retina. Increased microglia reactivity following ocular hypertension is also apparent in the optic nerve and optic tract [100]. Activated microglial cells in the LGN, the primary processing center for visual information received from the retina, have also been observed in glaucomatous monkeys in vivo with positron emission tomography imaging with $\left[{ }^{11}\right.$ C]PK11195 [120, 121]. Neuronal degeneration in the LGN has been reported to occur in experimental primate and human glaucoma [121-125], which can be correlated with microglia activation [121].

4.2. Age-Related Macular Degeneration. Age-related macular degeneration is a degenerative disease that affects RPE and photoreceptors in the human macula. Early stages of the disease feature deposition of extracellular debris, known as drusen, from the basal side of the RPE into Bruch's membrane (thin stratified extracellular matrix that separates RPE from the choriocapillaris). The disease may progress into two forms: a slowly developing geographic atrophy (GA) form, also known as dry AMD, and the fast developing neovascular AMD (nAMD), also known as wet form or exudative form (reviewed in $[126,127]$ ). Patients with GA exhibit areolar loss of the photoreceptors and RPE in the macula, whereas patients with nAMD exhibit angiogenesis and edema, from choroidal vessels that disrupt the overlying structures, including Bruch's membrane, RPE, and photoreceptor cells, resulting in focal retinal detachment and vision loss $[126,128]$.

No effective treatment or cure is currently available to treat the majority of AMD patients. Increased levels of vascular endothelial growth factor (VEGF) are detected in AMD patients, which can promote the exacerbation of choroidal neovascularization [129]. In fact, in spite of the use of antiVEGF therapy there is a persistent activity of neovascular lesions [130].

AMD is a multifactorial disease with numerous risk factors associated (age, smoking status, obesity, and dietary fat consumption) $[127,131]$ but it also has a genetic predisposition to its development $[132,133]$. Genome-wide association studies (GWAS) successively identified common risk variants localized in several candidate genes that are potentially involved in the development and progression of the disease [134-136]. Most of these genes are implicated in inflammatory pathway, implicating the immune system and inflammatory responses in the development and progression of AMD [137139]. The imbalance between parainflammation and chronic inflammation leads to tissue damage and contributes to the initiation of AMD (reviewed in [140]). The intravitreal administration of corticosteroids, which are commonly used to treat inflammatory eye diseases, decreases the expression of presenting antigens from the MHC-II of microglia in AMD patients [141]. Indeed, the levels of TNF are increased in AMD patients, which suggested anti-TNF as an effective tool in AMD treatment $[142,143]$. However, some studies demonstrated that some patients develop intraocular inflammatory reaction after intravitreal injection of infliximab $[144,145]$ and it has been shown that this treatment can be toxic depending on the dose administered [146].

In the laser photocoagulation animal model, known to induce choroidal neovascularization [147], the increased productions of intracellular adhesion molecule 1 (ICAM-1) and IL- 6 were prevented by administration of astaxanthin, known by its antioxidative and anti-inflammatory properties [148], reinforcing the role of the inflammatory response in the disease.

Recruitment of microglia has been associated with progression and severity of AMD. In mouse models of AMD, the release of VEGF by monocytes and microglia, recruited to the subretinal space, plays a crucial role in choroidal blood vessel growth $[149,150]$. In fact, blocking VEGF receptor inhibited the infiltration of microglia and macrophages in the laser photocoagulation animal model [151].

The strongest risk factor for the development of AMD is advanced age [152]. Interestingly, aged microglial cells present a reactive phenotype, which includes changes in morphology and surveillance impairment and may be correlated with AMD onset $[153,154]$. In fact, similarly to what occurs in aged mice [155], accumulation of microglia in the subretinal space has been reported in animal models of AMD [156, 157]. Moreover, drusen accumulation attracts macrophages during the initial phases of AMD [158]. Activated microglial cells are also detected in ONL of AMD patients, which has been proposed to contribute to photoreceptor degeneration [149, $159,160]$. Spectral domain optical coherence tomography (SD-OCT) is a valuable tool for the in vivo evaluation of single retinal layers (both the inner retina and the outer retina), which has been used for the evaluation of hyperreflective retinal spots. Recently, in wet AMD patients, hyperreflective dots were reported as small-sized punctiform hyperreflective elements, scattered throughout all retina layers but mainly located in the outer retina layers around fluid accumulation, consistent with activated microglia [161].

The association of polymorphisms in the CX3CR1 gene with AMD [149, 162, 163] provided additional evidence for the contribution of microglia to the onset and development of $\mathrm{AMD}$, since in the retina this gene is present only in microglia [164]. In CX3CR1-deficient mice, accumulation of microglia and macrophages in the subretinal space has been observed, contributing to drusen formation and photoreceptors degeneration $[149,165]$. Similarly, it has been proposed that mutations in the CX3CR1 gene induce recruitment of monocytes/microglia into the subretinal space in the eyes 
of patients with AMD [163]. Therefore, CX3CR1-dependent regulation of microglia recruitment in the subretinal space appears to be involved in the development of both wet and dry AMD $[149,150]$.

The complement system is a component of the innate immune response that provides a rapid defense against a range of immunological challenges and contributes to the maintenance of homeostasis. Although activation of the complement system has beneficial properties including promoting the clearance of debris, immune complexes, and apoptotic cells, it may also exacerbate degeneration if activated in an inappropriate manner [166]. Age-related alterations in gene expression associated with the complement system, namely, component complement 3 (C3), complement factor $\mathrm{B}(\mathrm{CFB})$, and complement factor $\mathrm{H}(\mathrm{CFH})$, have already been described, being also associated with the AMD onset [167]. Deregulation of the complement system is considered to be one of the major factors contributing to the etiology of AMD [168]. Component complement 3 is a key component of the complement system and adenovirus-mediated delivery of C3 to murine RPE induces significant functional and anatomic changes that reproduce many of the features of AMD [168]. Genome-wide association studies have found an association between C3 allele variant and a high risk for AMD [169-171]. In addition, retinal microglial cells were recently identified as the cell type responsible for the synthesis and deposit of C3 in the outer retina during damage [172] or aging [173], reinforcing their role in the development of AMD. Moreover, accumulation of A2E, a bisretinoid constituent of ocular lipofuscin, which accumulates in an aged-dependent manner in microglia present in the outer retina, was recently reported to favor the activation of the complement system [174].

4.3. Diabetic Retinopathy. Diabetes mellitus is a group of metabolic diseases characterized by elevated blood glucose levels (hyperglycemia). Two broad categories encompass the majority of diabetes: type 1 diabetes results from the inability to produce and secrete insulin and type 2 diabetes is characterized by a chronic insulin resistance which may be accompanied with a relative deficiency in insulin secretion. The resulting chronic hyperglycemia that occurs in both types of diabetes is associated with long-term damage, dysfunction, and failure of various organs, especially the kidneys, nerves, heart, blood vessels, and the eye [175].

Diabetic retinopathy is one of the most common complications of diabetes mellitus and the most frequent cause of new cases of blindness among adults aged 20-74 years [176]. After 20 years of diabetes, nearly all patients with type 1 and more than $60 \%$ of the patients with type 2 diabetes have some degree of retinopathy [176].

Clinically, diabetic retinopathy has been considered a microvascular disease, characterized by increased vascular permeability, due to the breakdown of BRB [177]. However, retinal neurons are also affected by diabetes [178]. In fact, we and others demonstrated that diabetic conditions induce neural cell death in retinal cultures [179], in streptozotocin(STZ-) induced type 1 diabetes rat model [180] and in diabetic patients [181]. Moreover, alterations in electroretinograms (ERG), which measure the electrical activity of the retina in response to light stimulus, were reported in diabetic patients [182-184] and in animal models of diabetes [185, 186]. These changes precede vascular alterations, suggesting that diabetic retinopathy should be classified as neurovascular disease [178], including a neurodegenerative component $[184,187]$.

Similar to other neurodegenerative diseases, diabetic retinopathy exhibits characteristics of low-grade chronic inflammation [188], with changes in retinal expression of inflammatory transcripts, which occurs in concert with functional changes in retinal permeability and apoptosis [189]. Proinflammatory cytokines, as TNF and IL-1 $\beta$, were found to be increased in the vitreous of patients with diabetic retinopathy [190-192], as well as IL-6 [193]. Among numerous effects promoted by TNF in the CNS, particularly in the retina, several are intimately related to alterations observed in diabetic retinopathy, such as increased endothelial cell permeability [194], breakdown of BRB [195], and induction of leukocyte adhesion [196]. Blockade of the TNF pathway with antibodies against TNF receptor 1 (TNFR1), one of the TNF receptors associated with cell death [197], prevented not only the retinal vascular alterations of diabetes [198-201], but also the death of retinal neurons induced by elevated glucose concentration [202]. IL-1 $\beta$, another proinflammatory cytokine, is also increased in the retina in experimental diabetes [203-205]. Interleukin converting enzyme/caspase1 , the enzyme responsible for the production of biological active IL-1 $\beta$ [206], is activated in the retina in both human and experimental diabetic retinopathy $[207,208]$. In diabetic rat retinas, the increase in IL- $1 \beta$ levels is correlated with an increase in BRB permeability [209] and treatment with cyclosporine $\mathrm{A}$, an anti-inflammatory drug, decreased both IL-1 $\beta$ levels and vascular permeability [210]. Experimental studies have also showed that intravitreal administration of IL-1 $\beta$ increases vascular permeability, which appears to be mediated by leukocyte adhesion, nuclear factor kappaB activation, and retinal capillary cell death [204, 211], suggesting that this inflammatory cytokine might also play an important role in the pathogenesis of diabetic retinopathy. Nitric oxide has been shown to play a role in diabetic retinopathy pathology. In fact, in diabetic retinas there is an upregulation of iNOS and endothelial nitric oxide synthase (eNOS) [212-214]. Increased NO levels may contribute to BRB breakdown, since increased BRB permeability was not observed in the retinas of diabetic iNOS knockout mice [214, 215].

Accumulation of microglia in subretinal space was observed in a rat model of spontaneous type 2 diabetes, where the pores formed in RPE cells were a migratory pathway for inflammatory cells (microglia/macrophages) [216]. Moreover, microglial cells releasing proinflammatory mediators have been detected in the retina of diabetic animals [203, 217-219] and in human diabetic patients [220], as early as electroretinographic modifications [221]. Recently, SD-OCT documented discrete hyperreflective spots, which may correspond to aggregates of activated microglia that increased with the clinical progression of diabetic retinopathy [222].

Taking the role of microglia in diabetic retinopathy, pharmacologic regulation of microglia activity has been 


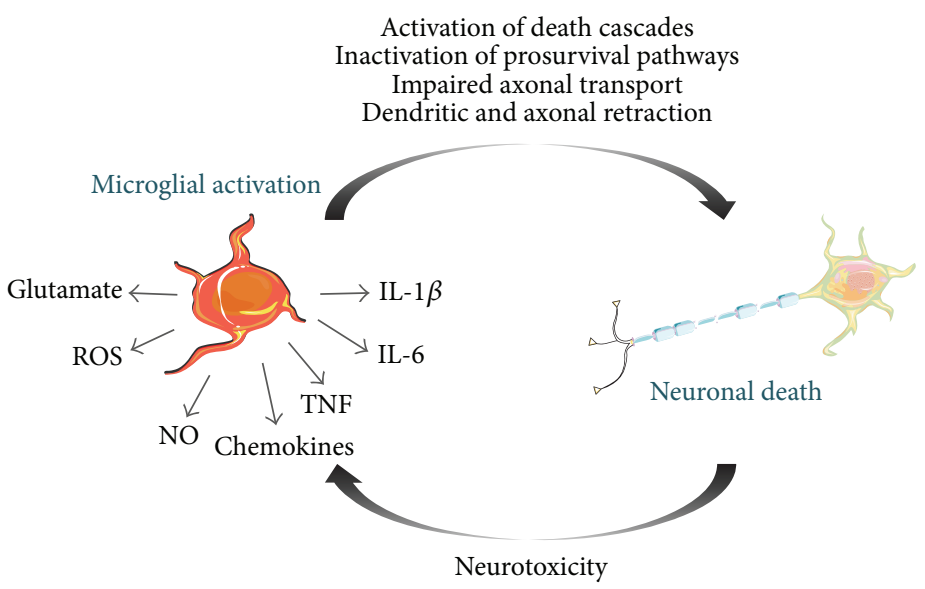

FIGURE 3: Relationships between microglial activation and neuronal cell death. In response to changes in the environment, microglia change to a more reactive phenotype, characterized by alterations in cell morphology, gene expression and proinflammatory mediators release. The sustained release of inflammatory factors perpetuates the neuroinflammatory process further activating microglia, which release proinflammatory and neurotoxic factors, contributing to neuronal dysfunction and to pathology.

tested as a rational approach to modulate early pathological events associated with diabetic retinopathy. Genistein, which is an isoflavonoid naturally occurring and a tyrosine kinase inhibitor, has been demonstrated to inhibit retinal microglia activation in diabetes-induced inflammation, through inhibition of ERK and p38 phosphorylation [223]. Minocycline, a second-generation, semisynthetic tetracycline with anti-inflammatory properties, inhibits activation of retinal microglia and proinflammatory cytokines expression in experimental diabetes [203].

Recently, some clinical trials have investigated whether the inhibition of microglia could be a therapeutic strategy for the treatment of diabetic retinopathy. In a pilot proofof-concept study (single-center, prospective, and open-label phase I/II clinical trial) with patients with diabetic macular edema, the treatment with minocycline improved visual function, central macular edema, and vascular leakage [224]. In a randomized, double-masked clinical trial in patients with severe nonproliferative diabetic retinopathy or nonhigh-risk proliferative diabetic retinopathy, doxycycline, a semisynthetic second-generation tetracycline also with antiinflammatory properties, improved foveal frequency doubling perimetry, suggesting a link between a low-dose of this oral anti-inflammatory agent and subclinical improvement in inner retinal function [225].

The role of microglia reactivity in diabetic retinopathy remains unclear and a better understanding of this process could improve the development of new therapeutic strategies.

\section{Conclusions}

There is mounting evidence demonstrating that microgliamediated neuroinflammation plays an important role in the pathophysiology of several retinal degenerative diseases, but it remains to clarify whether microglia reactivity is the cause or consequence of the neurodegenerative process (Figure 3).

The contribution of other cells cannot be discarded, since infiltration of immune circulating cells, like macrophages, or other cells like astrocytes or Müller cells may also participate in the inflammatory process in retinal diseases.

Therapeutic strategies designed for reducing inflammation may offer beneficial effects for the management of retinal degenerative diseases. More preclinical and clinical studies are definitely needed to clarify the role of microglia in the onset and progression of retinal neurodegenerative diseases. The complete inhibition of microglia will have to be taken into account in further studies, taking into consideration the crucial role of microglia in homeostasis.

\section{Conflict of Interests}

The authors declare that there is no conflict of interests regarding the publication of this paper.

\section{Acknowledgments}

This work was supported by Foundation for Science and Technology and COMPETE-FEDER (SFRH/BD/75839/2011, PTDC/BIM-MEC/0913/2012， PTDC/NEU-OSD/1113/2012, PEst-C/SAU/UI3282/2011-2013, and PEst-C/SAU/LA0001/ 2013-2014) and AIBILI, Portugal.

\section{References}

[1] R. Simó, M. Villarroel, L. Corraliza, C. Hernández, and M. Garcia-Ramírez, "The retinal pigment epithelium: something more than a constituent of the blood-retinal barrierimplications for the pathogenesis of diabetic retinopathy," Journal of Biomedicine and Biotechnology, vol. 2010, Article ID 190724, 15 pages, 2010.

[2] A. London, I. Benhar, and M. Schwartz, "The retina as a window to the brain-from eye research to CNS disorders," Nature Reviews Neurology, vol. 9, no. 1, pp. 44-53, 2013.

[3] R. Nelson, "Visual responses of Ganglion cells," in Webvision: The Organization of the Retina and Visual System, H. Kolb, E. Fernandez, and R. Nelson, Eds., Salt Lake City, Utah, USA, 1995. 
[4] A. Reichenbach and A. Bringmann, "New functions of müller cells," GLIA, vol. 61, no. 5, pp. 651-678, 2013.

[5] A. Bringmann and P. Wiedemann, "Müller glial cells in retinal disease," Ophthalmologica, vol. 227, no. 1, pp. 1-19, 2012.

[6] H. Kolb, "Glial cells of the retina," in Webvision: The Organization of the Retina and Visual System [Internet], H. Kolb, E. Fernandez, and R. Nelson, Eds., University of Utah Health Sciences Center, Salt Lake City, Utah, USA, 1995.

[7] A. M. Labin, S. K. Safuri, E. N. Ribak, and I. Perlman, "Müller cells separate between wavelengths to improve day vision with minimal effect upon night vision," Nature Communications, vol. 5, article 4319, 2014.

[8] H. Yao, T. Wang, J. Deng, D. Liu, X. Li, and J. Deng, “The development of blood-retinal barrier during the interaction of astrocytes with vascular wall cells," Neural Regeneration Research, vol. 9, no. 10, pp. 1047-1054, 2014.

[9] K. Helmut, U.-K. Hanisch, M. Noda, and A. Verkhratsky, "Physiology of microglia," Physiological Reviews, vol. 91, no. 2, pp. 461-553, 2011.

[10] H. Kettenmann, F. Kirchhoff, and A. Verkhratsky, "Microglia: new roles for the synaptic stripper," Neuron, vol. 77, no. 1, pp. 10-18, 2013.

[11] P. M. Bilimoria and B. Stevens, "Microglia function during brain development: new insights from animal models," Brain Research, 2014.

[12] D. P. Schafer, E. K. Lehrman, A. G. Kautzman et al., "Microglia sculpt postnatal neural circuits in an activity and complementdependent manner," Neuron, vol. 74, no. 4, pp. 691-705, 2012.

[13] A. R. Bialas and B. Stevens, "TGF- $\beta$ signaling regulates neuronal Clq expression and developmental synaptic refinement," Nature Neuroscience, vol. 16, no. 12, pp. 1773-1782, 2013.

[14] K. W. Ashwell, H. Holländer, W. Streit, and J. Stone, "The appearance and distribution of microglia in the developing retina of the rat," Visual neuroscience, vol. 2, no. 5, pp. 437-448, 1989.

[15] U. B. Eyo and L.-J. Wu, "Bidirectional microglia-neuron communication in the healthy brain," Neural Plasticity, vol. 2013, Article ID 456857, 10 pages, 2013.

[16] M. E. Carwile, R. B. Culbert, R. L. Sturdivant, and T. W. Kraft, "Rod outer segment maintenance is enhanced in the presence of BFGF, CNTF and GDNF," Experimental Eye Research, vol. 66, no. 6, pp. 791-805, 1998.

[17] T. Harada, C. Harada, S. Kohsaka et al., "Microglia-Müller glia cell interactions control neurotrophic factor production during light-induced retinal degeneration," Journal of Neuroscience, vol. 22, no. 21, pp. 9228-9236, 2002.

[18] Y. Li, X.-F. Du, C.-S. Liu, Z.-L. Wen, and J.-L. Du, "Reciprocal regulation between resting microglial dynamics and neuronal activity in vivo," Developmental Cell, vol. 23, no. 6, pp. 1189-1202, 2012.

[19] M. Wang and W. T. Wong, "Microglia-Müller cell interactions in the retina," Advances in Experimental Medicine and Biology, vol. 801, pp. 333-338, 2014.

[20] M. Wang, X. Wang, L. Zhao et al., "Macroglia-microglia interactions via TSPO signaling regulates microglial activation in the mouse retina," Journal of Neuroscience, vol. 34, no. 10, pp. 3793-3806, 2014.

[21] F. Ginhoux, S. Lim, G. Hoeffel, D. Low, and T. Huber, "Origin and differentiation of microglia," Frontiers in Cellular Neuroscience, vol. 7, 2013.
[22] E. Polazzi and B. Monti, "Microglia and neuroprotection: from in vitro studies to therapeutic applications," Progress in Neurobiology, vol. 92, no. 3, pp. 293-315, 2010.

[23] W. Y. Chan, S. Kohsaka, and P. Rezaie, "The origin and cell lineage of microglia-new concepts," Brain Research Reviews, vol. 53, no. 2, pp. 344-354, 2007.

[24] O. Butovsky, M. P. Jedrychowski, C. S. Moore et al., "Identification of a unique TGF- $\beta$-dependent molecular and functional signature in microglia," Nature Neuroscience, vol. 17, no. 1, pp. 131-143, 2014.

[25] E. L. Gautiar, T. Shay, J. Miller et al., "Gene-expression profiles and transcriptional regulatory pathways that underlie the identity and diversity of mouse tissue macrophages," Nature Immunology, vol. 13, no. 11, pp. 1118-1128, 2012.

[26] C. M. Diaz-Araya, J. M. Provis, P. L. Penfold, and F. A. Billson, "Development of microglial topography in human retina," The Journal of Comparative Neurology, vol. 363, no. 1, pp. 53-68, 1995.

[27] H. Xu, M. Chen, E. J. Mayer, J. V. Forrester, and A. D. Dick, "Turnover of resident retinal microglia in the normal adult mouse," GLIA, vol. 55, no. 11, pp. 1189-1198, 2007.

[28] T. A. Albini, R. C. Wang, B. Reiser, E. Zamir, G. S. Wu, and N. A. Rao, "Microglial stability and repopulation in the retina," British Journal of Ophthalmology, vol. 89, no. 7, pp. 901-903, 2005.

[29] B. Ajami, J. L. Bennett, C. Krieger, W. Tetzlaff, and F. M. V. Rossi, "Local self-renewal can sustain CNS microglia maintenance and function throughout adult life," Nature Neuroscience, vol. 10, no. 12, pp. 1538-1543, 2007.

[30] M. Chen, J. Zhao, C. Luo et al., "Para-inflammation-mediated retinal recruitment of bone marrow-derived myeloid cells following whole-body irradiation is CCL2 dependent," Glia, vol. 60, no. 5, pp. 833-842, 2012.

[31] T. Huang, J. Cui, L. Li, P. F. Hitchcock, and Y. Li, "The role of microglia in the neurogenesis of zebrafish retina," Biochemical and Biophysical Research Communications, vol. 421, no. 2, pp. 214-220, 2012.

[32] A. Sierra, J. Navascués, M. A. Cuadros et al., "Expression of inducible nitric oxide synthase (iNOS) in microglia of the developing quail retina," PLOS ONE, vol. 9, no. 8, Article ID e106048, 2014.

[33] R. M. Ferrer-Martín, D. Martín-Oliva, A. Sierra et al., "Microglial cells in organotypic cultures of developing and adult mouse retina and their relationship with cell death," Experimental Eye Research, vol. 121, pp. 42-57, 2014.

[34] D. A. Hume, V. H. Perry, and S. Gordon, "Immunohistochemical localization of a macrophage-specific antigen in developing mouse retina: phagocytosis of dying neurons and differentiation in microglial cells to form a regular array in the plexiform layers," The Journal of Cell Biology, vol. 97, no. 1, pp. 253-257, 1983.

[35] R. G. Ellis-Behnke, R. A. Jonas, and J. B. Jonas, "The microglial system in the eye and brain in response to stimuli in vivo," Journal of Glaucoma, vol. 22, pp. S32-S35, 2013.

[36] R. T. Sasmono, D. Oceandy, J. W. Pollard et al., "A macrophage colony-stimulating factor receptor-green fluorescent protein transgene is expressed throughout the mononuclear phagocyte system of the mouse," Blood, vol. 101, no. 3, pp. 1155-1163, 2003.

[37] D. H. Frankel, B. H. Hanusa, and J. A. Zitelli, "New primary nonmelanoma skin cancer in patients with a history of squamous cell carcinoma of the skin: implications and recommendations for follow-up," Journal of the American Academy of Dermatology, vol. 26, no. 5, pp. 720-726, 1992. 
[38] L. Chen, P. Yang, and A. Kijlstra, "Distribution, markers, and functions of retinal microglia," Ocular Immunology and Inflammation, vol. 10, no. 1, pp. 27-39, 2002.

[39] J. M. Provis, C. M. Diaz, and P. L. Penfold, "Microglia in human retina: a heterogeneous population with distinct ontogenies," Perspectives on Developmental Neurobiology, vol. 3, no. 3, pp. 213-222, 1996.

[40] J. E. Lee, K. J. Liang, R. N. Fariss, and W. T. Wong, "Ex vivo dynamic imaging of retinal microglia using time-lapse confocal microscopy," Investigative Ophthalmology and Visual Science, vol. 49, no. 9, pp. 4169-4176, 2008.

[41] A. M. Santos, R. Calvente, M. Tassi et al., "Embryonic and postnatal development of microglial cells in the mouse retina," The Journal of Comparative Neurology, vol. 506, no. 2, pp. 224239, 2008.

[42] P. Sobrado-Calvo, M. Vidal-Sanz, and M. P. Villegas-Pérez, "Rat retinal microglial cells under normal conditions, after optic nerve section, and after optic nerve section and intravitreal injection of trophic factors or macrophage inhibitory factor," The Journal of Comparative Neurology, vol. 501, no. 6, pp. 866878, 2007.

[43] D. Checchin, F. Sennlaub, E. Levavasseur, M. Leduc, and S. Chemtob, "Potential role of microglia in retinal blood vessel formation," Investigative Ophthalmology and Visual Science, vol. 47, no. 8, pp. 3595-3602, 2006.

[44] H. Crehan, J. Hardy, and J. Pocock, "Microglia, Alzheimer's disease, and complement," International Journal of Alzheimer's Disease, vol. 2012, Article ID 983640, 10 pages, 2012.

[45] S. Sugama, T. Takenouchi, B. P. Cho, T. H. Joh, M. Hashimoto, and H. Kitani, "Possible roles of microglial cells for neurotoxicity in clinical neurodegenerative diseases and experimental animal models," Inflammation \& Allergy-Drug Targets, vol. 8, no. 4, pp. 277-284, 2009.

[46] T. C. Frank-Cannon, L. T. Alto, F. E. McAlpine, and M. G. Tansey, "Does neuroinflammation fan the flame in neurodegenerative diseases?" Molecular Neurodegeneration, vol. 4, no. 1, article 47, 2009.

[47] J. Rogers, D. Mastroeni, B. Leonard, J. Joyce, and A. Grover, "Neuroinflammation in Alzheimer's disease and Parkinson's disease: are microglia pathogenic in either disorder?" International Review of Neurobiology, vol. 82, pp. 235-246, 2007.

[48] M. L. Block and J.-S. Hong, "Microglia and inflammationmediated neurodegeneration: multiple triggers with a common mechanism," Progress in Neurobiology, vol. 76, no. 2, pp. 77-98, 2005.

[49] S. B. Beynon and F. R. Walker, "Microglial activation in the injured and healthy brain: what are we really talking about? Practical and theoretical issues associated with the measurement of changes in microglial morphology," Neuroscience, vol. 225, pp. 162-171, 2012.

[50] S. David and A. Kroner, "Repertoire of microglial and macrophage responses after spinal cord injury," Nature Reviews Neuroscience, vol. 12, no. 7, pp. 388-399, 2011.

[51] M. E. Lull and M. L. Block, "Microglial activation and chronic neurodegeneration," Neurotherapeutics, vol. 7, no. 4, pp. 354$365,2010$.

[52] D. Pascolini and S. P. Mariotti, "Global estimates of visual impairment: 2010," British Journal of Ophthalmology, vol. 96, no. 5, pp. 614-618, 2012.

[53] S. Resnikoff, D. Pascolini, D. Etya'ale et al., "Global data on visual impairment in the year 2002," Bulletin of the World Health Organization, vol. 82, no. 11, pp. 844-851, 2004.
[54] T. Langmann, "Microglia activation in retinal degeneration," Journal of Leukocyte Biology, vol. 81, no. 6, pp. 1345-1351, 2007.

[55] M. Karlstetter, S. Ebert, and T. Langmann, "Microglia in the healthy and degenerating retina: insights from novel mouse models," Immunobiology, vol. 215, no. 9-10, pp. 685-691, 2010.

[56] W. Cheung, L. Guo, and M. F. Cordeiro, "Neuroprotection in glaucoma: drug-based approaches," Optometry and Vision Science, vol. 85, no. 6, pp. E406-E416, 2008.

[57] N. Fuse, "Genetic bases for glaucoma," Tohoku Journal of Experimental Medicine, vol. 221, no. 1, pp. 1-10, 2010.

[58] K. Chiu, T.-F. Chan, A. Wu, I. Y.-P. Leung, K.-F. So, and R. C.-C. Chang, "Neurodegeneration of the retina in mouse models of Alzheimer's disease: what can we learn from the retina?" Age, vol. 34, no. 3, pp. 633-649, 2012.

[59] J. Qu, D. Wang, and C. L. Grosskreutz, "Mechanisms of retinal ganglion cell injury and defense in glaucoma," Experimental Eye Research, vol. 91, no. 1, pp. 48-53, 2010.

[60] R. F. Brubaker, "Delayed functional loss in glaucoma. LII Edward Jackson Memorial Lecture," The American Journal of Ophthalmology, vol. 121, no. 5, pp. 473-483, 1996.

[61] A. Baltmr, J. Duggan, S. Nizari, T. E. Salt, and M. F. Cordeiro, "Neuroprotection in glaucoma-is there a future role?" Experimental Eye Research, vol. 91, no. 5, pp. 554-566, 2010.

[62] A. C. Bessero and P. G. Clarke, "Neuroprotection for optic nerve disorders," Current Opinion in Neurology, vol. 23, no. 1, pp. 10$15,2010$.

[63] M. F. Cordeiro and L. A. Levin, "Clinical evidence for neuroprotection in glaucoma," The American Journal of Ophthalmology, vol. 152, no. 5, pp. 715-716, 2011.

[64] S. Balaiya, J. Edwards, T. Tillis, V. Khetpal, and K. V. Chalam, "Tumor necrosis factor-alpha (TNF- $\alpha$ ) levels in aqueous humor of primary open angle glaucoma," Clinical Ophthalmology, vol. 5, no. 1, pp. 553-556, 2011.

[65] L. Yuan and A. H. Neufeld, "Tumor necrosis factor- $\alpha$ : a potentially neurodestructive cytokine produced by glia in the human glaucomatous optic nerve head," Glia, vol. 32, no. 1, pp. 42-50, 2000.

[66] G. Tezel, X. Yang, J. Yang, and M. B. Wax, "Role of tumor necrosis factor receptor-1 in the death of retinal ganglion cells following optic nerve crush injury in mice," Brain Research, vol. 996, no. 2, pp. 202-212, 2004.

[67] G. Tezel and M. B. Wax, "Increased production of tumor necrosis factor- $\alpha$ by glial cells exposed to simulated ischemia or elevated hydrostatic pressure induces apoptosis in cocultured retinal ganglion cells," Journal of Neuroscience, vol. 20, no. 23, pp. 8693-8700, 2000.

[68] L. Yuan and A. H. Neufeld, "Activated microglia in the human glaucomatous optic nerve head," Journal of Neuroscience Research, vol. 64, no. 5, pp. 523-532, 2001.

[69] B. Cvenkel, A. N. Kopitar, and A. Ihan, "Inflammatory molecules in aqueous humour and on ocular surface and glaucoma surgery outcome," Mediators of Inflammation, vol. 2010, Article ID 939602, 7 pages, 2010.

[70] K.-H. Chen, C.-C. Wu, S. Roy, S.-M. Lee, and J.-H. Liu, "Increased interleukin-6 in aqueous humor of neovascular glaucoma," Investigative Ophthalmology \& Visual Science, vol. 40, no. 11, pp. 2627-2632, 1999.

[71] R. M. Sappington and D. J. Calkins, "Contribution of TRPV1 to microglia-derived IL- 6 and NFא B translocation with elevated hydrostatic pressure," Investigative Ophthalmology and Visual Science, vol. 49, no. 7, pp. 3005-3017, 2008. 
[72] E. C. Johnson, T. A. Doser, W. O. Cepurna et al., "Cell proliferation and interleukin-6-type cytokine signaling are implicated by gene expression responses in early optic nerve head injury in rat glaucoma," Investigative Ophthalmology and Visual Science, vol. 52, no. 1, pp. 504-518, 2011.

[73] G. Chidlow, J. P. M. Wood, A. Ebneter, and R. J. Casson, "Interleukin-6 is an efficacious marker of axonal transport disruption during experimental glaucoma and stimulates neuritogenesis in cultured retinal ganglion cells," Neurobiology of Disease, vol. 48, no. 3, pp. 568-581, 2012.

[74] S. M. Sims, L. Holmgren, H. M. Cathhart, and R. Sappington, "Spatial regulation of interleukin-6 signaling in response to neurodegenerative stressors in the retina," American Journal of Neurodegenerative Disease, vol. 1, no. 2, pp. 168-179, 2012.

[75] J. Chua, M. Vania, C. M. G. Cheung et al., "Expression profile of inflammatory cytokines in aqueous from glaucomatous eyes," Molecular Vision, vol. 18, pp. 431-438, 2012.

[76] A. H. Neufeld, S.-I. Kawai, S. Das et al., "Loss of retinal ganglion cells following retinal ischemia: the role of inducible nitric oxide synthase," Experimental Eye Research, vol. 75, no. 5, pp. 521-528, 2002.

[77] K. J. Cho, J. H. Kim, H.-Y. L. Park, and C. K. Park, "Glial cell response and iNOS expression in the optic nerve head and retina of the rat following acute high IOP ischemiareperfusion," Brain Research, vol. 1403, pp. 67-77, 2011.

[78] G. Tezel, L. Y. Li, R. V. Patil, and M. B. Wax, "TNF- $\alpha$ and TNF$\alpha$ receptor-1 in the retina of normal and glaucomatous eyes," Investigative Ophthalmology and Visual Science, vol. 42, no. 8, pp. 1787-1794, 2001.

[79] T. Nakazawa, C. Nakazawa, A. Matsubara et al., “Tumor necrosis factor- $\alpha$ mediates oligodendrocyte death and delayed retinal ganglion cell loss in a mouse model of glaucoma," The Journal of Neuroscience, vol. 26, no. 49, pp. 12633-12641, 2006.

[80] M. M. Al-Gayyar and N. M. Elsherbiny, "Contribution of TNF$\alpha$ to the development of retinal neurodegenerative disorders," European Cytokine Network, vol. 24, no. 1, pp. 27-36, 2013.

[81] G. Tezel and M. B. Wax, "Increased production of tumor necrosis factor- $\alpha$ by glial cells exposed to simulated ischemia or elevated hydrostatic pressure induces apoptosis in cocultured retinal ganglion cells," The Journal of Neuroscience, vol. 20, no. 23, pp. 8693-8700, 2000.

[82] M. Roh, Y. Zhang, Y. Murakami et al., "Etanercept, a widely used inhibitor of tumor necrosis factor- $\alpha$ (TNF- $\alpha$ ), prevents retinal ganglion cell loss in a rat model of glaucoma," PLoS ONE, vol. 7, no. 7, Article ID e40065, 2012.

[83] L. Markiewicz, I. Majsterek, K. Przybylowska et al., "Gene polymorphisms of the $M M P 1, M M P 9, M M P 12, I L-1 \beta$ and TIMP1 and the risk of primary open-angle glaucoma," Acta Ophthalmologica, vol. 91, no. 7, pp. e516-e523, 2013.

[84] C. Nathan and Q. W. Xie, "Regulation of biosynthesis of nitric oxide," The Journal of Biological Chemistry, vol. 269, no. 19, pp. 13725-13728, 1994.

[85] U. Förstermann and W. C. Sessa, "Nitric oxide synthases: regulation and function," European Heart Journal, vol. 33, no. 7, pp. 829-837, 2012.

[86] A. H. Neufeld, R. Hemandez, and M. Gonzalez, "Nitric oxide synthase in the human glaucomatous optic nerve head," Archives of Ophthalmology, vol. 115, no. 4, pp. 497-503, 1997.

[87] L. Vidal, F. Díaz, A. Villena, M. Moreno, J. G. Campos, and I. P. D. Vargas, "Nitric oxide synthase in retina and optic nerve head of rat with increased intraocular pressure and effect of timolol," Brain Research Bulletin, vol. 70, no. 4-6, pp. 406-413, 2006.
[88] S. Shareef, A. Sawada, and A. H. Neufeld, "Isoforms of nitric oxide synthase in the optic nerves of rat eyes with chronic moderately elevated intraocular pressure," Investigative Ophthalmology and Visual Science, vol. 40, no. 12, pp. 2884-2891, 1999.

[89] A. H. Neufeld, A. Sawada, and B. Becker, "Inhibition of nitricoxide synthase 2 by aminoguanidine provides neuroprotection of retinal ganglion cells in a rat model of chronic glaucoma," Proceedings of the National Academy of Sciences of the United States of America, vol. 96, no. 17, pp. 9944-9948, 1999.

[90] R. M. Sappington and D. J. Calkins, "Pressure-induced regulation of IL-6 in retinal glial cells: Involvement of the ubiquitin/proteasome pathway and $\mathrm{NF} \kappa \mathrm{B}$," Investigative Ophthalmology and Visual Science, vol. 47, no. 9, pp. 3860-3869, 2006.

[91] R. M. Sappington, M. Chan, and D. J. Calkins, "Interleukin6 protects retinal ganglion cells from pressure-induced death," Investigative Ophthalmology and Visual Science, vol. 47, no. 7, pp. 2932-2942, 2006.

[92] F. H. Grus, S. C. Joachim, D. Wuenschig, J. Rieck, and N. Pfeiffer, "Autoimmunity and glaucoma," Journal of Glaucoma, vol. 17, no. 1, pp. 79-84, 2008.

[93] J. Reichelt, S. C. Joachim, N. Pfeiffer, and F. H. Grus, "Analysis of autoantibodies against human retinal antigens in sera of patients with glaucoma and ocular hypertension," Current Eye Research, vol. 33, no. 3, pp. 253-261, 2008.

[94] S. C. Joachim, N. Pfeiffer, and F. H. Grus, "Autoantibodies in patients with glaucoma: a comparison of IgG serum antibodies against retinal, optic nerve, and optic nerve head antigens," Graefe's Archive for Clinical and Experimental Ophthalmology, vol. 243, no. 8, pp. 817-823, 2005.

[95] S. C. Joachim, O. W. Gramlich, P. Laspas et al., "Retinal ganglion cell loss is accompanied by antibody depositions and increased levels of microglia after immunization with retinal antigens," PLoS ONE, vol. 7, no. 7, Article ID e40616, 2012.

[96] P. Laspas, O. W. Gramlich, H. D. Müller et al., "Autoreactive antibodies and loss of retinal ganglion cells in rats induced by immunization with ocular antigens," Investigative Ophthalmology \& Visual Science, vol. 52, no. 12, pp. 8835-8848, 2011.

[97] S. Taylor, C. J. Calder, J. Albon, J. T. Erichsen, M. E. Boulton, and J. E. Morgan, "Involvement of the CD200 receptor complex in microglia activation in experimental glaucoma," Experimental Eye Research, vol. 92, no. 5, pp. 338-343, 2011.

[98] G. Tezel, "The role of glia, mitochondria, and the immune system in glaucoma," Investigative Ophthalmology \& Visual Science, vol. 50, no. 3, pp. 1001-1012, 2008.

[99] A. Bosco, M. R. Steele, and M. L. Vetter, "Early microglia activation in a mouse model of chronic glaucoma," Journal of Comparative Neurology, vol. 519, no. 4, pp. 599-620, 2011.

[100] A. Ebneter, R. J. Casson, J. P. M. Wood, and G. Chidlow, "Microglial activation in the visual pathway in experimental glaucoma: spatiotemporal characterization and correlation with axonal injury," Investigative Ophthalmology and Visual Science, vol. 51, no. 12, pp. 6448-6460, 2010.

[101] E. C. Johnson, Y. Guo, W. O. Cepurna, and J. C. Morrison, "Neurotrophin roles in retinal ganglion cell survival: lessons from rat glaucoma models," Experimental Eye Research, vol. 88, no. 4, pp. 808-815, 2009.

[102] A. Pascale, F. Drago, and S. Govoni, "Protecting the retinal neurons from glaucoma: lowering ocular pressure is not enough," Pharmacological Research, vol. 66, no. 1, pp. 19-32, 2012. 
[103] R. Vohra, J. C. Tsai, and M. Kolko, "The role of inflammation in the pathogenesis of glaucoma," Survey of Ophthalmology, vol. 58, no. 4, pp. 311-320, 2013.

[104] A. Bosco, S. D. Crish, M. R. Steele et al., "Early reduction of microglia activation by irradiation in a model of chronic glaucoma," PLoS ONE, vol. 7, no. 8, Article ID e43602, 2012.

[105] H. A. Quigley, "Experimental glaucoma damage mechanism.," Archives of Ophthalmology, vol. 101, no. 8, pp. 1301-1302, 1983.

[106] S. Thanos, "The relationship of microglial cells to dying neurons during natural neuronal cell death and axotomyinduced degeneration of the rat retina," European Journal of Neuroscience, vol. 3, no. 12, pp. 1189-1207, 1991.

[107] E. Schuetz and S. Thanos, "Neuro-glial interactions in the adult rat retina after reaxotomy of ganglion cells: examination of neuron survival and phagocytic microglia using fluorescent tracers," Brain Research Bulletin, vol. 62, no. 5, pp. 391-396, 2004.

[108] C. Zhang, T. T. Lam, and M. O. Tso, "Heterogeneous populations of microglia/macrophages in the retina and their activation after retinal ischemia and reperfusion injury," Experimental Eye Research, vol. 81, no. 6, pp. 700-709, 2005.

[109] D. M. Inman and P. J. Horner, "Reactive nonproliferative gliosis predominates in a chronic mouse model of glaucoma," Glia, vol. 55, no. 9, pp. 942-953, 2007.

[110] R. Fan, F. Xu, M. L. Previti et al., "Minocycline reduces microglial activation and improves behavioral deficits in a transgenic model of cerebral microvascular amyloid," The Journal of Neuroscience, vol. 27, no. 12, pp. 3057-3063, 2007.

[111] H. Levkovitch-Verbin, Y. Waserzoog, S. Vander, D. Makarovsky, and I. Piven, "Minocycline upregulates pro-survival genes and downregulates pro-apoptotic genes in experimental glaucoma," Graefe's Archive for Clinical and Experimental Ophthalmology, vol. 252, pp. 761-772, 2014.

[112] S. F. Abcouwer, C. M. Lin, S. Shanmugam, A. Muthusamy, A. J. Barber, and D. A. Antonetti, "Minocycline prevents retinal inflammation and vascular permeability following ischemiareperfusion injury," Journal of Neuroinflammation, vol. 10, article 149, 2013.

[113] A. Bosco, D. M. Inman, M. R. Steele et al., "Reduced retina microglial activation and improved optic nerve integrity with minocycline treatment in the DBA/2J mouse model of glaucoma," Investigative Ophthalmology \& Visual Science, vol. 49, no. 4, pp. 1437-1446, 2008.

[114] A. H. Neufeld, "Microglia in the optic nerve head and the region of parapapillary chorioretinal atrophy in glaucoma," Archives of Ophthalmology, vol. 117, no. 8, pp. 1050-1056, 1999.

[115] R. Naskar, M. Wissing, and S. Thanos, "Detection of early neuron degeneration and accompanying microglial responses in the retina of a rat model of glaucoma," Investigative Ophthalmology and Visual Science, vol. 43, no. 9, pp. 2962-2968, 2002.

[116] R. de Hoz, B. I. Gallego, A. I. Ramírez et al., "Rod-like microglia are restricted to eyes with laser-induced ocular hypertension but absent from the microglial changes in the contralateral untreated eye," PLoS ONE, vol. 8, no. 12, Article ID e83733, 2013.

[117] B. I. Gallego, J. J. Salazar, R. de $\mathrm{Hoz}$ et al., "IOP induces upregulation of GFAP and MHC-II and microglia reactivity in mice retina contralateral to experimental glaucoma," Journal of Neuroinflammation, vol. 9, article 92, 2012.

[118] J. Qu and T. C. Jakobs, "The time course of gene expression during reactive gliosis in the optic nerve," PLoS ONE, vol. 8, no. 6, Article ID e67094, 2013.
[119] B. Rojas, B. I. Gallego, A. I. Ramirez et al., "Microglia in mouse retina contralateral to experimental glaucoma exhibit multiple signs of activation in all retinal layers," Journal of Neuroinflammation, vol. 11, no. 1, p. 133, 2014.

[120] K. Lmamura, H. Onoe, M. Shimazawa et al., "Molecular imaging reveals unique degenerative changes in experimental glaucoma," NeuroReport, vol. 20, no. 2, pp. 139-144, 2009.

[121] M. Shimazawa, Y. Ito, Y. Inokuchi et al., "An alteration in the lateral geniculate nucleus of experimental glaucoma monkeys: in vivo positron emission tomography imaging of glial activation," PLoS ONE, vol. 7, no. 1, Article ID e30526, 2012.

[122] Y. Ito, M. Shimazawa, Y.-N. Chen et al., "Morphological changes in the visual pathway induced by experimental glaucoma in Japanese monkeys," Experimental Eye Research, vol. 89, no. 2, pp. 246-255, 2009.

[123] N. Gupta, L.-C. Ang, L. N. de Tilly, L. Bidaisee, and Y. H. Yücel, "Human glaucoma and neural degeneration in intracranial optic nerve, lateral geniculate nucleus, and visual cortex," The British Journal of Ophthalmology, vol. 90, no. 6, pp. 674-678, 2006.

[124] N. Gupta, G. Greenberg, L. N. de Tilly, B. Gray, M. Polemidiotis, and Y. H. Yücel, "Atrophy of the lateral geniculate nucleus in human glaucoma detected by magnetic resonance imaging," British Journal of Ophthalmology, vol. 93, no. 1, pp. 56-60, 2009.

[125] A. J. Weber, H. Chen, W. C. Hubbard, and P. L. Kaufman, "Experimental glaucoma and cell size, density, and number in the primate lateral geniculate nucleus," Investigative Ophthalmology and Visual Science, vol. 41, no. 6, pp. 1370-1379, 2000.

[126] M. Van Lookeren Campagne, J. Lecouter, B. L. Yaspan, and W. Ye, "Mechanisms of age-related macular degeneration and therapeutic opportunities," The Journal of Pathology, vol. 232, no. 2, pp. 151-164, 2014.

[127] D. Ardeljan and C.-C. Chan, "Aging is not a disease: distinguishing age-related macular degeneration from aging," Progress in Retinal and Eye Research, vol. 37, pp. 68-89, 2013.

[128] H. R. Coleman, C.-C. Chan, F. L. Ferris III, and E. Y. Chew, "Agerelated macular degeneration," The Lancet, vol. 372, no. 9652, pp. $1835-1845,2008$.

[129] R. Hera, M. Keramidas, M. Peoc'h, M. Mouillon, J.-P. Romanet, and J.-J. Feige, "Expression of VEGF and angiopoietins in subfoveal membranes from patients with age-related macular degeneration," American Journal of Ophthalmology, vol. 139, no. 4, pp. 589-596, 2005.

[130] D. Barthelmes, R. Walton, A. E. Campain et al., "Outcomes of persistently active neovascular age-related macular degeneration treated with VEGF inhibitors: observational study data," The British Journal of Ophthalmology, 2014.

[131] L. G. Fritsche, R. N. Fariss, D. Stambolian, G. R. Abecasis, C. A. Curcio, and A. Swaroop, "Age-related macular degeneration: genetics and biology coming together," Annual Review of Genomics and Human Genetics, vol. 15, no. 1, pp. 151-171, 2014.

[132] L. Ersoy, T. Ristau, M. Hahn et al., "Genetic and environmental risk factors for age-related macular degeneration in persons 90 years and older," Investigative Ophthalmology and Visual Science, vol. 55, no. 3, pp. 1842-1847, 2014.

[133] F. Grassmann, L. G. Fritsche, C. N. Keilhauer, I. M. Heid, and B. H. F. Weber, "Modelling the genetic risk in age-related macular degeneration," PLoS ONE, vol. 7, no. 5, Article ID e37979, 2012.

[134] K. Horie-Inoue and S. Inoue, "Genomic aspects of age-related macular degeneration," Biochemical and Biophysical Research Communications, vol. 452, no. 2, pp. 263-275, 2014. 
[135] J. N. Cooke Bailey, M. A. Pericak-Vance, and J. L. Haines, "Genome-wide association studies: getting to pathogenesis, the role of inflammation/complement in age-related macular degeneration," Cold Spring Harbor Perspectives in Medicine, vol. 4, no. 12, Article ID a017186, 2014.

[136] L. G. Fritsche, W. Chen, M. Schu et al., "Seven new loci associated with age-related macular degeneration," Nature Genetics, vol. 45, no. 4, pp. 433-439, 2013.

[137] D. H. Anderson, R. F. Mullins, G. S. Hageman, and L. V. Johnson, "A role for local inflammation in the formation of drusen in the aging eye," American Journal of Ophthalmology, vol. 134, no. 3, pp. 411-431, 2002.

[138] L. V. Johnson, W. P. Leitner, M. K. Staples, and D. H. Anderson, "Complement activation and inflammatory processes in drusen formation and age related macular degeneration," Experimental Eye Research, vol. 73, no. 6, pp. 887-896, 2001.

[139] P. L. Penfold, M. C. Madigan, M. C. Gillies, and J. M. Provis, "Immunological and aetiological aspects of macular degeneration," Progress in Retinal and Eye Research, vol. 20, no. 3, pp. 385-414, 2001.

[140] M. Nita, A. Grzybowski, F. J. Ascaso, and V. Huerva, "Agerelated macular degeneration in the aspect of chronic lowgrade inflammation (pathophysiological parainflammation)," Mediators of Inflammation, vol. 2014, Article ID 930671, 10 pages, 2014.

[141] P. L. Penfold, J. G. Wong, J. Gyory, and F. A. Billson, "Effects of triamcinolone acetonide on microglial morphology and quantitative expression of MHC-II in exudative age-related macular degeneration," Clinical and Experimental Ophthalmology, vol. 29, no. 3, pp. 188-192, 2001.

[142] P. G. Theodossiadis, V. S. Liarakos, P. P. Sfikakis, I. A. Vergados, and G. P. Theodossiadis, "Intravitreal administration of the antitumor necrosis factor agent infliximab for neovascular agerelated macular degeneration," American Journal of Ophthalmology, vol. 147, no. 5, pp. 825.el-830.el, 2009.

[143] P. G. Theodossiadis, N. N. Markomichelakis, and P. P. Sfikakis, "Tumor necrosis factor antagonists: preliminary evidence for an emerging approach in the treatment of ocular inflammation," Retina, vol. 27, no. 4, pp. 399-413, 2007.

[144] M. Giganti, P. M. Beer, N. Lemanski, C. Hartman, J. Schartman, and N. Falk, "Adverse events after intravitreal infliximab (Remicade)," Retina, vol. 30, no. 1, pp. 71-80, 2010.

[145] A. Mirshahi, R. Hoehn, K. Lorenz, C. Kramann, and H. Baatz, "Anti-tumor necrosis factor alpha for retinal diseases: current knowledge and future concepts," Journal of Ophthalmic and Vision Research, vol. 7, no. 1, pp. 39-44, 2012.

[146] P. G. Theodossiadis, V. S. Liarakos, P. P. Sfikakis et al., "Intravitreal administration of the anti-TNF monoclonal antibody infliximab in the rabbit," Graefe's Archive for Clinical and Experimental Ophthalmology, vol. 247, no. 2, pp. 273-281, 2009.

[147] V. Lambert, J. Lecomte, S. Hansen et al., "Laser-induced choroidal neovascularization model to study age-related macular degeneration in mice," Nature Protocols, vol. 8, no. 11, pp. 2197-2211, 2013.

[148] K. Izumi-Nagai, N. Nagai, K. Ohgami et al., "Inhibition of choroidal neovascularization with an anti-inflammatory carotenoid astaxanthin," Investigative Ophthalmology and Visual Science, vol. 49, no. 4, pp. 1679-1685, 2008.

[149] C. Combadière, C. Feumi, W. Raoul et al., "CX3CR1-dependent subretinal microglia cell accumulation is associated with cardinal features of age-related macular degeneration," The Journal of Clinical Investigation, vol. 117, no. 10, pp. 2920-2928, 2007.
[150] T. A. Krause, A. F. Alex, D. R. Engel, C. Kurts, and N. Eter, "VEGF-production by CCR2-dependent macrophages contributes to laser-induced choroidal neovascularization," PLoS ONE, vol. 9, no. 4, Article ID e94313, 2014.

[151] H. Huang, R. Parlier, J.-K. Shen, G. A. Lutty, and S. A. Vinores, "VEGF receptor blockade markedly reduces retinal microglia/ macrophage infiltration into laser-induced CNV," PLOS ONE, vol. 8, no. 8, Article ID e71808, 2013.

[152] L. K. Cheung and A. Eaton, "Age-related macular degeneration.," Pharmacotherapy, vol. 33, no. 8, pp. 838-855, 2013.

[153] M. Karlstetter and T. Langmann, "Microglia in the aging retina," in Retinal Degenerative Diseases, vol. 801 of Advances in Experimental Medicine and Biology, pp. 207-212, Springer, New York, NY, USA, 2014.

[154] M. R. Damani, L. Zhao, A. M. Fontainhas, J. Amaral, R. N. Fariss, and W. T. Wong, "Age-related alterations in the dynamic behavior of microglia," Aging Cell, vol. 10, no. 2, pp. 263-276, 2011.

[155] H. Xu, M. Chen, A. Manivannan, N. Lois, and J. V. Forrester, "Age-dependent accumulation of lipofuscin in perivascular and subretinal microglia in experimental mice," Aging Cell, vol. 7, no. 1, pp. 58-68, 2008.

[156] F. Cruz-Guilloty, A. M. Saeed, J. J. Echegaray et al., "Infiltration of proinflammatory M1 macrophages into the outer retina precedes damage in a mouse model of age-related macular degeneration," International Journal of Inflammation, vol. 2013, Article ID 503725, 12 pages, 2013.

[157] J. G. Hollyfield, V. L. Perez, and R. G. Salomon, "A hapten generated from an oxidation fragment of docosahexaenoic acid is sufficient to initiate age-related macular degeneration," Molecular Neurobiology, vol. 41, no. 2-3, pp. 290-298, 2010.

[158] M. C. Killingsworth, J. P. Sarks, and S. H. Sarks, "Macrophages related to Bruch's membrane in age-related macular degeneration," Eye, vol. 4, no. 4, pp. 613-621, 1990.

[159] P. L. Penfold, S. C. K. Liew, M. C. Madigan, and J. M. Provis, "Modulation of major histocompatibility complex class II expression in retinas with age-related macular degeneration," Investigative Ophthalmology \& Visual Science, vol. 38, no. 10, pp. 2125-2133, 1997.

[160] N. Gupta, K. E. Brown, and A. H. Milam, "Activated microglia in human retinitis pigmentosa, late-onset retinal degeneration, and age-related macular degeneration," Experimental Eye Research, vol. 76, no. 4, pp. 463-471, 2003.

[161] G. Coscas, U. de Benedetto, F. Coscas et al., "Hyperreflective dots: a new spectral-domain optical coherence tomography entity for follow-up and prognosis in exudative age-related macular degeneration," Ophthalmologica, vol. 229, no. 1, pp. 3237, 2013.

[162] J. Tuo, B. C. Smith, C. M. Bojanowski et al., "The involvement of sequence variation and expression of CX3CR1 in the pathogenesis of age-related macular degeneration," The FASEB Journal, vol. 18, no. 11, pp. 1297-1299, 2004.

[163] C. C. Chan, J. Tuo, C. M. Bojanowski, K. G. Csaky, and W. R. Green, "Detection of CX3CR1 single nucleotide polymorphism and expression on archived eyes with age-related macular degeneration," Histology and Histopathology, vol. 20, no. 3, pp. 857-863, 2005.

[164] W. Raoul, C. Auvynet, S. Camelo et al., "CCL2/CCR2 and CX3CL1/CX3CR1 chemokine axes and their possible involvement in age-related macular degeneration," Journal of Neuroinflammation, vol. 7, article 87, 2010. 
[165] F. Sennlaub, C. Auvynet, B. Calippe et al., "CCR2 ${ }^{+}$monocytes infiltrate atrophic lesions in age-related macular disease and mediate photoreceptor degeneration in experimental subretinal inflammation in Cx3crl deficient mice," EMBO Molecular Medicine, vol. 5, no. 11, pp. 1775-1793, 2013.

[166] M. P. Kawa, A. Machalinska, D. Roginska, and B. Machalinski, "Complement system in pathogenesis of AMD: dual player in degeneration and protection of retinal tissue," Journal of Immunology Research, vol. 2014, Article ID 483960, 12 pages, 2014.

[167] W. Ma, R. Cojocaru, N. Gotoh et al., "Gene expression changes in aging retinal microglia: relationship to microglial support functions and regulation of activation," Neurobiology of Aging, vol. 34, no. 10, pp. 2310-2321, 2013.

[168] S. M. Cashman, A. Desai, K. Ramo, and R. Kumar-Singh, "Expression of complement component 3 (C3) from an adenovirus leads to pathology in the murine retina," Investigative Ophthalmology and Visual Science, vol. 52, no. 6, pp. 3436-3445, 2011.

[169] X. Zhan, D. E. Larson, C. Wang et al., "Identification of a rare coding variant in complement 3 associated with age-related macular degeneration," Nature Genetics, vol. 45, no. 11, pp. 13751379, 2013.

[170] J. M. Seddon, Y. Yu, E. C. Miller et al., "Rare variants in CFI, $C 3$ and $C 9$ are associated with high risk of advanced age-related macular degeneration," Nature Genetics, vol. 45, no. 11, pp. 13661373, 2013.

[171] E. C. Schramm, S. J. Clark, M. P. Triebwasser, S. Raychaudhuri, J. M. Seddon, and J. P. Atkinson, "Genetic variants in the complement system predisposing to age-related macular degeneration: a review," Molecular Immunology, vol. 61, no. 2, pp. 118-125, 2014.

[172] M. Rutar, R. Natoli, P. Kozulin, K. Valter, P. Gatenby, and J. M. Provis, "Analysis of complement expression in lightinduced retinal degeneration: synthesis and deposition of C3 by microglia/macrophages is associated with focal photoreceptor degeneration," Investigative Ophthalmology and Visual Science, vol. 52, no. 8, pp. 5347-5358, 2011.

[173] M. Rutar, K. Valter, R. Natoli, and J. M. Provis, "Synthesis and propagation of complement $\mathrm{C} 3$ by microglia/monocytes in the aging retina," PLoS ONE, vol. 9, no. 4, Article ID e93343, 2014.

[174] W. Ma, S. Coon, L. Zhao, R. N. Fariss, and W. T. Wong, "A2E accumulation influences retinal microglial activation and complement regulation," Neurobiology of Aging, vol. 34, no. 3, pp. 943-960, 2013.

[175] American Diabetes Association, "Diagnosis and classification of diabetes mellitus," Diabetes Care, vol. 33, Supplement 1, pp. S62-S69, 2009.

[176] D. S. Fong, L. Aiello, T. W. Gardner et al., "Diabetic retinopathy," Diabetes Care, vol. 26, supplement 1, pp. S99-S102, 2003.

[177] J. Cunha-Vaz, J. R. F. de Abreu, and A. J. Campos, "Early breakdown of the blood retinal barrier in diabetes," British Journal of Ophthalmology, vol. 59, no. 11, pp. 649-656, 1975.

[178] A. J. Barber, "A new view of diabetic retinopathy: a neurodegenerative disease of the eye," Progress in NeuroPsychopharmacology and Biological Psychiatry, vol. 27, no. 2, pp. 283-290, 2003.

[179] A. R. Santiago, A. J. Cristóvão, P. F. Santos, C. M. Carvalho, and A. F. Ambrósio, "High glucose induces caspase-independent cell death in retinal neural cells," Neurobiology of Disease, vol. 25, no. 3, pp. 464-472, 2007.

[180] H. P. Hammes, H. J. Federoff, and M. Brownlee, "Nerve growth factor prevents both neuroretinal programmed cell death and capillary pathology in experimental diabetes," Molecular Medicine, vol. 1, no. 5, pp. 527-534, 1995.

[181] L. A. Kerrigan, D. J. Zack, H. A. Quigley, S. D. Smith, and M. E. Pease, "TUNEL-positive ganglion cells in human primary open-angle glaucoma," Archives of Ophthalmology, vol. 115, no. 8, pp. 1031-1035, 1997.

[182] S. E. Simonsen, "The value of the oscillatory potential in selecting juvenile diabetics at risk of developing proliferative retinopathy," Acta Ophthalmologica, vol. 58, no. 6, pp. 865-878, 1980.

[183] J. Kizawa, S. Machida, T. Kobayashi, Y. Gotoh, and D. Kurosaka, "Changes of oscillatory potentials and photopic negative response in patients with early diabetic retinopathy," Japanese Journal of Ophthalmology, vol. 50, no. 4, pp. 367-373, 2006.

[184] A. Reis, C. Mateus, P. Melo, J. Figueira, J. Cunha-Vaz, and M. Castelo-Branco, "Neuroretinal dysfunction with intact bloodretinal barrier and absent vasculopathy in type 1 diabetes," Diabetes, vol. 63, no. 11, pp. 3926-3937, 2014.

[185] K. Mihály, S. Tóth, L. Szlávik, A. Tóth, and P. Csermely, "Attenuation of diabetic retinopathy by the molecular chaperoneinducer amino acid analogue canavanine in streptozotocindiabetic rats," Cellular and Molecular Life Sciences, vol. 54, no. 10, pp. 1154-1160, 1998.

[186] H. Matsubara, M. Kuze, M. Sasoh, N. Ma, M. Furuta, and Y. Uji, "Time-dependent course of electroretinograms in the spontaneous diabetic Goto-Kakizaki rat," Japanese Journal of Ophthalmology, vol. 50, no. 3, pp. 211-216, 2006.

[187] H. W. van Dijk, F. D. Verbraak, P. H. B. Kok et al., "Early neurodegeneration in the retina of type 2 diabetic patients," Investigative Ophthalmology and Visual Science, vol. 53, no. 6, pp. 2715-2719, 2012.

[188] J. Tang and T. S. Kern, "Inflammation in diabetic retinopathy," Progress in Retinal and Eye Research, vol. 30, no. 5, pp. 343-358, 2011.

[189] R. M. Brucklacher, K. M. Patel, H. D. VanGuilder et al., "Whole genome assessment of the retinal response to diabetes reveals a progressive neurovascular inflammatory response," BMC Medical Genomics, vol. 1, article 26, 2008.

[190] A. M. A. El Asrar, D. Maimone, P. H. Morse, S. Gregory, and A. T. Reder, "Cytokines in the vitreous of patients with proliferative diabetic retinopathy," The American Journal of Ophthalmology, vol. 114, no. 6, pp. 731-736, 1992.

[191] N. Demircan, B. G. Safran, M. Soylu, A. A. Ozcan, and S. Sizmaz, "Determination of vitreous interleukin-1 (IL-1) and tumour necrosis factor (TNF) levels in proliferative diabetic retinopathy," Eye, vol. 20, no. 12, pp. 1366-1369, 2006.

[192] Y. Liu, M. B. Costa, and C. Gerhardinger, "IL-1 $\beta$ is upregulated in the diabetic retina and retinal vessels: cell-specific effect of high glucose and IL-1 $\beta$ autostimulation," PLoS ONE, vol. 7, no. 5, Article ID e36949, 2012.

[193] H. Funatsu, H. Yamashita, H. Noma, T. Mimura, T. Yamashita, and S. Hori, "Increased levels of vascular endothelial growth factor and interleukin- 6 in the aqueous humor of diabetics with macular edema," American Journal of Ophthalmology, vol. 133, no. 1, pp. 70-77, 2002.

[194] C. A. Aveleira, C. M. Lin, S. F. Abcouwer, A. F. Ambrosio, and D. A. Antonetti, “TNF-alpha signals through PKCzeta/NFkappaB to alter the tight junction complex and increase retinal endothelial cell permeability," Diabetes, vol. 59, no. 11, pp. 28722882,2010

[195] J. D. Luna, C.-C. Chan, N. L. Derevjanik et al., "Bloodretinal barrier (BRB) breakdown in experimental autoimmune 
uveoretinitis: comparison with vascular endothelial growth factor, tumor necrosis factor $\alpha$, and interleukin- $1 \beta$-mediated breakdown," Journal of Neuroscience Research, vol. 49, no. 3, pp. 268-280, 1997.

[196] K. Koizumi, V. Poulaki, S. Doehmen et al., "Contribution of TNF- $\alpha$ to leukocyte adhesion, vascular leakage, and apoptotic cell death in endotoxin-induced uveitis in vivo," Investigative Ophthalmology and Visual Science, vol. 44, no. 5, pp. 2184-2191, 2003.

[197] M. P. Boldin, T. M. Goncharov, Y. V. Goltsev, and D. Wallach, "Involvement of $\mathrm{MACH}$, a novel MORT1/FADD-interacting protease, in Fas/APO-1- and TNF receptor-induced cell death," Cell, vol. 85, no. 6, pp. 803-815, 1996.

[198] A. M. Joussen, S. Doehmen, M. L. Le et al., "TNF- $\alpha$ mediated apoptosis plays an important role in the development of early diabetic retinopathy and long-term histopathological alterations," Molecular Vision, vol. 15, pp. 1418-1428, 2009.

[199] A. M. Joussen, V. Poulaki, A. Tsujikawa et al., "Suppression of diabetic retinopathy with angiopoietin-1," The American Journal of Pathology, vol. 160, no. 5, pp. 1683-1693, 2002.

[200] Y. Behl, P. Krothapalli, T. Desta, S. Roy, and D. T. Graves, "FOXO1 plays an important role in enhanced microvascular cell apoptosis and microvascular cell loss in type 1 and type 2 diabetic rats," Diabetes, vol. 58, no. 4, pp. 917-925, 2009.

[201] Y. Behl, P. Krothapalli, T. Desta, A. DiPiazza, S. Roy, and D. T. Graves, "Diabetes-enhanced tumor necrosis factor- $\alpha$ production promotes apoptosis and the loss of retinal microvascular cells in type 1 and type 2 models of diabetic retinopathy," The American Journal of Pathology, vol. 172, no. 5, pp. 1411-1418, 2008.

[202] G. N. Costa, J. Vindeirinho, C. Cavadas, A. F. Ambrósio, and P. F. Santos, "Contribution of TNF receptor 1 to retinal neural cell death induced by elevated glucose," Molecular and Cellular Neuroscience, vol. 50, no. 1, pp. 113-123, 2012.

[203] J. K. Krady, A. Basu, C. M. Allen et al., "Minocycline reduces proinflammatory cytokine expression, microglial activation, and caspase- 3 activation in a rodent model of diabetic retinopathy," Diabetes, vol. 54, no. 5, pp. 1559-1565, 2005.

[204] R. A. Kowluru and S. Odenbach, "Role of interleukin- $1 \beta$ in the pathogenesis of diabetic retinopathy," The British Journal of Ophthalmology, vol. 88, no. 10, pp. 1343-1347, 2004.

[205] A. Carmo, J. G. Cunha-Vaz, A. P. Carvalho, and M. C. Lopes, "Nitric oxide synthase activity in retinas from non-insulindependent diabetic Goto-Kakizaki rats: correlation with bloodretinal barrier permeability," Nitric Oxide, vol. 4, no. 6, pp. 590$596,2000$.

[206] C. A. Dinarello, "Biologic basis for interleukin-1 in disease," Blood, vol. 87, no. 6, pp. 2095-2147, 1996.

[207] S. Mohr, A. Xi, J. Tang, and T. S. Kern, "Caspase activation in retinas of diabetic and galactosemic mice and diabetic patients," Diabetes, vol. 51, no. 4, pp. 1172-1179, 2002.

[208] J. A. Vincent and S. Mohr, "Inhibition of caspase-1/interleukin$1 \beta$ signaling prevents degeneration of retinal capillaries in diabetes and galactosemia," Diabetes, vol. 56, no. 1, pp. 224-230, 2007.

[209] C. Aveleira, Á. Castilho, F. Baptista et al., "High glucose and interleukin-1 $\beta$ downregulate interleukin-1 type I receptor (IL1RI) in retinal endothelial cells by enhancing its degradation by a lysosome-dependent mechanism," Cytokine, vol. 49, no. 3, pp. 279-286, 2010.

[210] A. Carmo, J. G. Cunha-Vaz, A. P. Carvalho, and M. C. Lopes, "Effect of cyclosporin-A on the blood-retinal barrier permeability in streptozotocin-induced diabetes," Mediators of Inflammation, vol. 9, no. 5, pp. 243-248, 2000.

[211] S. D. Bamforth, S. L. Lightman, and J. Greenwood, "Interleukin$1 \beta$-induced disruption of the retinal vascular barrier of the central nervous system is mediated through leukocyte recruitment and histamine," The American Journal of Pathology, vol. 150, no. 1, pp. 329-340, 1997.

[212] A. B. El-Remessy, M. Ali Behzadian, G. Abou-Mohamed, T. Franklin, R. W. Caldwell, and R. B. Caldwell, "Experimental diabetes causes breakdown of the blood-retina barrier by a mechanism involving tyrosine nitration and increases in expression of vascular endothelial growth factor and urokinase plasminogen activator receptor," The American Journal of Pathology, vol. 162, no. 6, pp. 1995-2004, 2003.

[213] M. Takeda, F. Mori, A. Yoshida et al., "Constitutive nitric oxide synthase is associated with retinal vascular permeability in early diabetic rats," Diabetologia, vol. 44, no. 8, pp. 1043-1050, 2001.

[214] E. C. Leal, A. Manivannan, K.-I. Hosoya et al., "Inducible nitric oxide synthase isoform is a key mediator of leukostasis and blood-retinal barrier breakdown in diabetic retinopathy," Investigative Ophthalmology and Visual Science, vol. 48, no. 11, pp. 5257-5265, 2007.

[215] L. Zheng, Y. Du, C. Miller et al., "Critical role of inducible nitric oxide synthase in degeneration of retinal capillaries in mice with streptozotocin-induced diabetes," Diabetologia, vol. 50, no. 9, pp. 1987-1996, 2007.

[216] S. Omri, F. Behar-Cohen, Y. de Kozak et al., "Microglia/macrophages migrate through retinal epithelium barrier by a transcellular route in diabetic retinopathy: role of PKCzeta in the Goto Kakizaki rat model," The American Journal of Pathology, vol. 179, no. 2, pp. 942-953, 2011.

[217] E. Rungger-Brändle, A. A. Dosso, and P. M. Leuenberger, "Glial reactivity, an early feature of diabetic retinopathy," Investigative Ophthalmology \& Visual Science, vol. 41, no. 7, pp. 1971-1980, 2000.

[218] X.-X. Zeng, Y.-K. Ng, and E.-A. Ling, "Neuronal and microglial response in the retina of streptozotocin-induced diabetic rats," Visual Neuroscience, vol. 17, no. 3, pp. 463-471, 2000.

[219] A. J. Barber, D. A. Antonetti, T. S. Kern et al., "The Ins2 $2^{\text {Akita }}$ mouse as a model of early retinal complications in diabetes," Investigative Ophthalmology and Visual Science, vol. 46, no. 6, pp. 2210-2218, 2005.

[220] H.-Y. Zeng, W. R. Green, and M. O. M. Tso, "Microglial activation in human diabetic retinopathy," Archives of Ophthalmology, vol. 126, no. 2, pp. 227-232, 2008.

[221] D. Gaucher, J. A. Chiappore, M. Pâques et al., "Microglial changes occur without neural cell death in diabetic retinopathy," Vision Research, vol. 47, no. 5, pp. 612-623, 2007.

[222] S. Vujosevic, S. Bini, G. Midena, M. Berton, E. Pilotto, and E. Midena, "Hyperreflective intraretinal spots in diabetics without and with nonproliferative diabetic retinopathy: an in vivo study using spectral domain OCT," Journal of Diabetes Research, vol. 2013, Article ID 491835, 5 pages, 2013.

[223] A. S. Ibrahim, M. M. El-Shishtawy, A. Peña Jr., and G. I. Liou, "Genistein attenuates retinal inflammation associated with diabetes by targeting of microglial activation," Molecular Vision, vol. 16, pp. 2033-2042, 2010.

[224] C. A. Cukras, P. Petrou, E. Y. Chew, C. B. Meyerle, and W. T. Wong, "Oral minocycline for the treatment of diabetic macular 
edema (DME): results of a phase I/II clinical study," Investigative Ophthalmology and Visual Science, vol. 53, no. 7, pp. 3865-3874, 2012.

[225] I. U. Scott, G. R. Jackson, D. A. Quillen et al., "Effect of doxycycline vs placebo on retinal function and diabetic retinopathy progression in patients with severe nonproliferative or nonhigh-risk proliferative diabetic retinopathy: a randomized clinical trial," JAMA Ophthalmology, vol. 132, no. 5, pp. 535-543, 2014. 


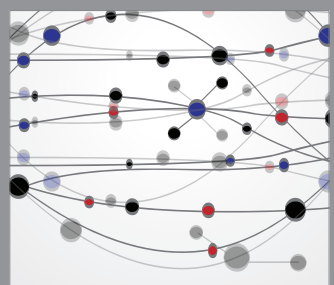

The Scientific World Journal
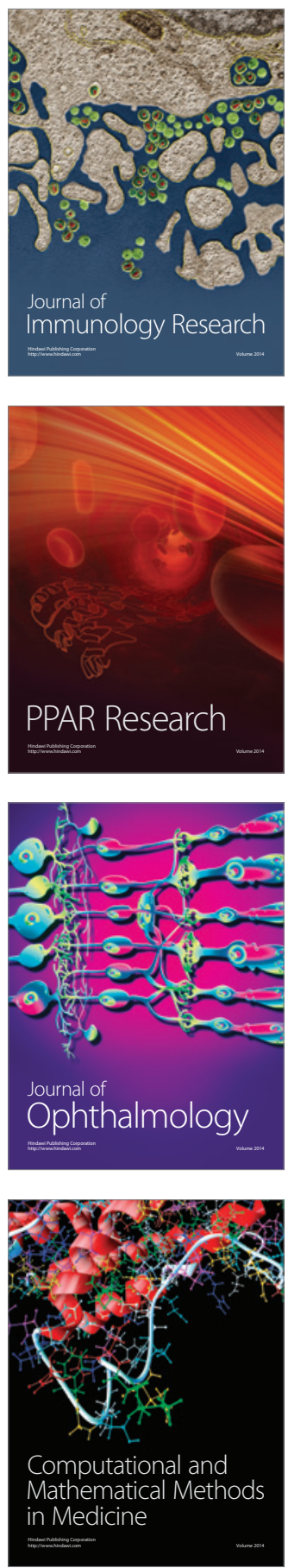

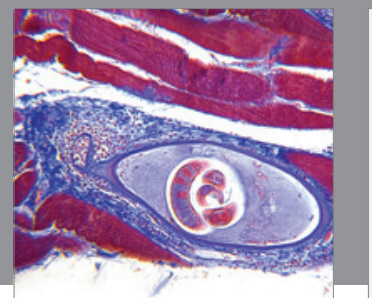

Gastroenterology

Research and Practice
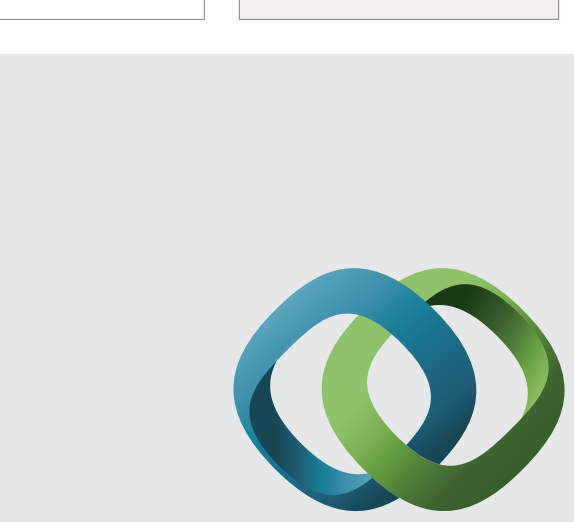

\section{Hindawi}

Submit your manuscripts at

http://www.hindawi.com
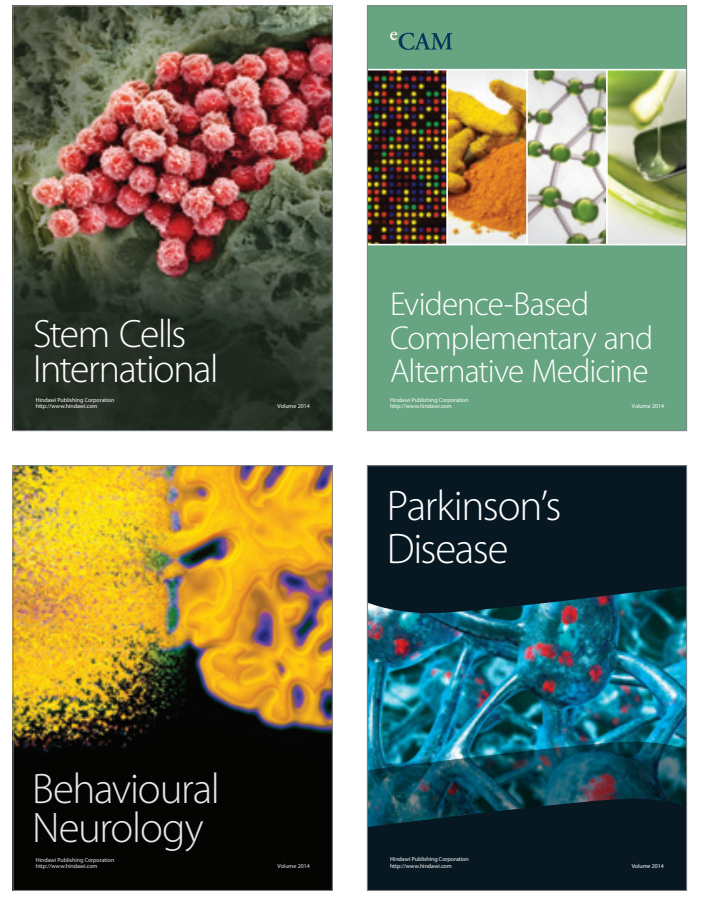
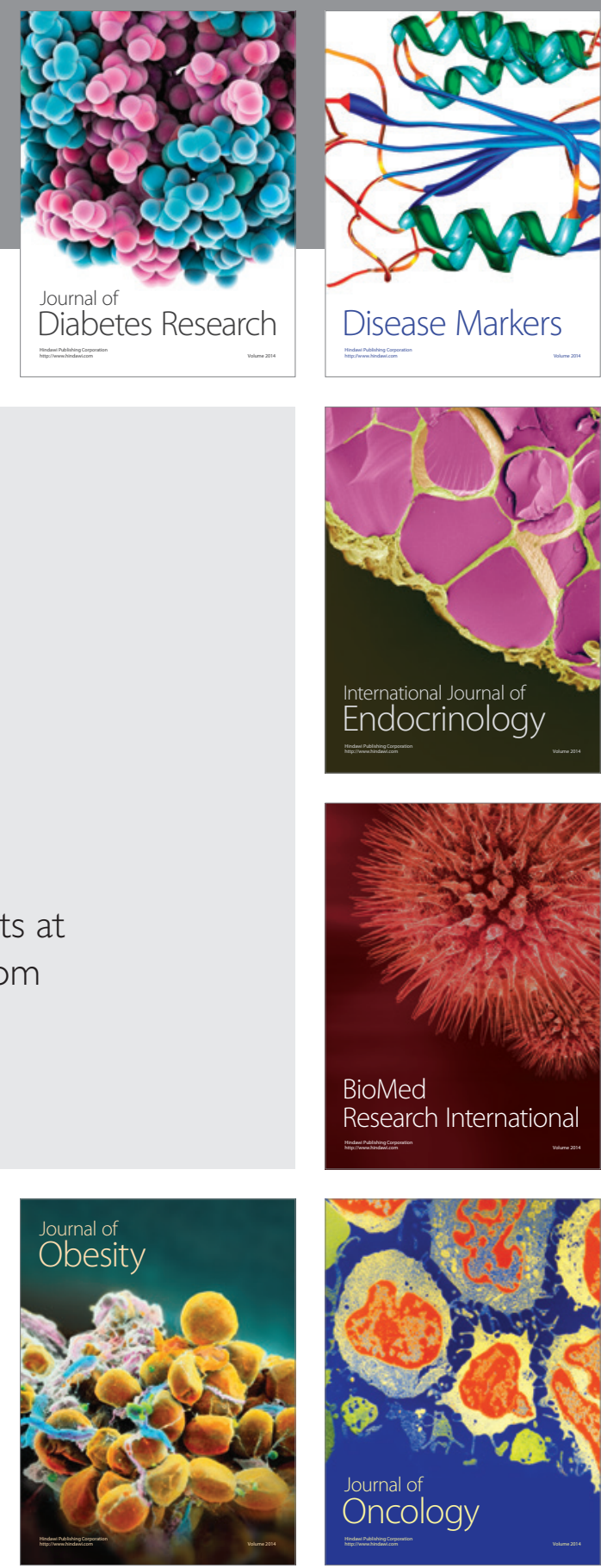

Disease Markers
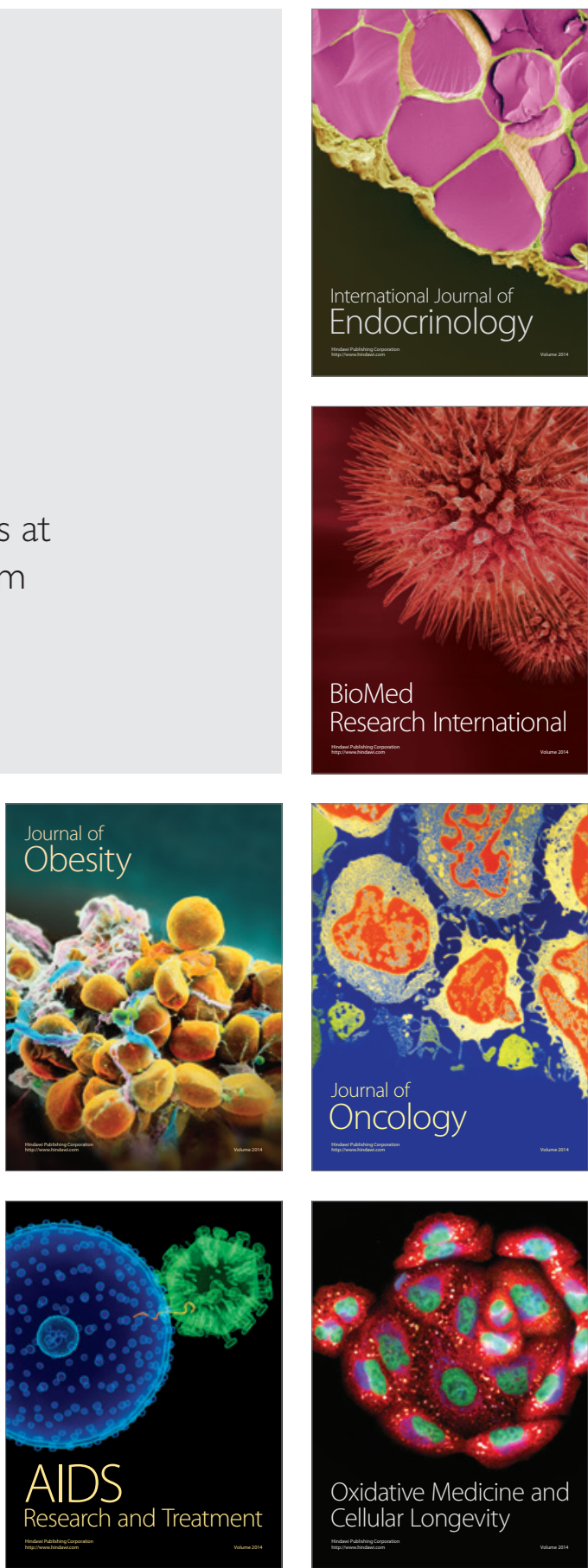